\title{
Finding the perfect match between nanoparticles and microfluidics to respond to cancer challenges
}

\author{
F. Raquel Maia, PhD ${ }^{\mathrm{a}, \mathrm{b}, \mathrm{c}, *}$, Rui L. Reis, PhD, DSc, Hon. Causa MD, Hon Causa PhD ${ }^{\mathrm{a}, \mathrm{b}, \mathrm{c}}$, \\ Joaquim M. Oliveira, $\mathrm{PhD}^{\mathrm{a}, \mathrm{b}, \mathrm{c}}$ \\ a3B's Research Group, I3Bs - Research Institute on Biomaterials, Biodegradables and Biomimetics, University of Minho, Headquarters of the European \\ Institute of Excellence on Tissue Engineering and Regenerative Medicine, AvePark, Parque de Ciência e Tecnologia, Zona Industrial da Gandra, Barco, \\ Guimarães, Portugal \\ ${ }^{\mathrm{b}}$ ICVS/3B's PT Government Associate Lab, Braga, Guimarães, Portugal \\ ${ }^{\mathrm{c}}$ The Discoveries Centre for Regenerative and Precision Medicine, Headquarters at University of Minho, Barco, Guimarães, Portugal
}

Revised 19 November 2019

\begin{abstract}
The clinical translation of new cancer theranostic has been delayed by inherent cancer's heterogeneity. Additionally, this delay has been enhanced by the lack of an appropriate in vitro model, capable to produce accurate data. Nanoparticles and microfluidic devices have been used to obtain new and more efficient strategies to tackle cancer challenges. On one hand, nanoparticles-based therapeutics can be modified to target specific cells, and/or molecules, and/or modified with drugs, releasing them over time. On the other hand, microfluidic devices allow the exhibition of physiologically complex systems, incorporation of controlled flow, and control of the chemical environment. Herein, we review the use of nanoparticles and microfluidic devices to address different cancer challenges, such as detection of CTCs and biomarkers, point-of-care devices for early diagnosis and improvement of therapies. The future perspectives of cancer challenges are also addressed herein.
\end{abstract}

(C) 2019 Elsevier Inc. All rights reserved.

Key words: Microfluidic devices; nanoparticles; cancer theranostic; point-of-care devices; drug delivery

Cancer mortality rates have been growing along the years and are estimated to increase by $70 \%$ within the next two decades. ${ }^{1}$ Within these, $90 \%$ of deaths are associated with cancer metastasis. In contrary to other cells, tumour cells are genomically unstable which enables them to proliferate continually, resist cell death, induce angiogenesis, and to metastasize to distant organs through lymph and blood vessels migration, giving rise to a second tumour. ${ }^{2}$ While tumour cells are in circulation, they are termed circulating tumour cells (CTCs) and they can undergo further mutations, leading to different outcomes of the primary tumour cells, ${ }^{3}$ resulting in therapy resistance and disease progression. ${ }^{4}$ These complex and heterogeneous scenarios have urged scientists to study a myriad of strategies, involving namely CTCs, ${ }^{5,6}$ proteins $^{7,8}$ and nucleic $\operatorname{acids}^{9,10}$ for the development of new cancer theranostic tools. An efficient diagnosis test would allow early detection of cancer and consequently improve cancer patients' survival. Additional- ly, early detection could diminish the cost associated with cancer treatments. Still, cancer heterogeneity has played important roles in delaying clinical translation of such approaches, as also as the lack of an appropriate in vitro model has postponed it, as discussed previously. ${ }^{11,12}$

During the last decades, our capacity to develop new strategies for theranostic has advanced significantly. Approaches for cancer diagnosis and treatment have become more sophisticated and reliable, and high throughput processes have been applied due to forward-thinking technologies, such as the use of nanoparticles and microfluidic devices. ${ }^{13,14}$

The use of nanoparticles for diagnosis has been intensively pursued, once they can be easily modified. In this reasoning, avidin modified nanoparticles are the most common modification found. ${ }^{15}$ Avidin modified nanoparticles can strongly connect with biotin modified moieties without hindering their biological properties.

\footnotetext{
*Corresponding author at: 3B's Research Group, I3Bs - Research Institute on Biomaterials, Biodegradables and Biomimetics, University of Minho, Headquarters of the European Institute of Excellence on Tissue Engineering and Regenerative Medicine, AvePark, Parque de Ciência e Tecnologia, Zona Industrial da Gandra, 4805-017 Barco, Guimarães, Portugal.

E-mail address: raquel.maia@i3bs.uminho.pt (F.R. Maia).
} 
Nanoparticles modification allows the targeting of specific cells, and/or molecules, and/or modification with drugs, releasing them over time. For example, nano-sized particles with core-shell structures were developed by Zhang and colleagues ${ }^{16}$ to release daunorubicin intracellularly. When submitted to $\mathrm{pH}$ around 5-6, the drug was efficiently released in cancer cells' nuclei. In a different example, 6-mercaptopurine was conjugated with carboxymethyl chitosan as a targeted drug release strategy to tackle leukaemia. ${ }^{17}$ The authors successfully observed that intracellular drug release was higher in cancer cells than normal cells.

These nanometre size structures are very attractive due to the capability to pass through the permeable vessels present in the tumour and then be retained there due to the reduced lymphatic drainage (i.e. enhanced permeation and retention (EPR) effect).-

18 Thus, nanoparticles can be used for imaging, diagnose and therapy as described in detailed elsewhere. ${ }^{19-21}$

Nonetheless, and despite the promising future of using nanoparticles in cancer research, they present low efficiency. Different reasons can be pointed out to hinder its efficiency, such as interactions with cells and the high interstitial fluid pressure. In this sense, an appropriate model capable of mimic these complex interactions could promote the adjustment of their design and their translation into clinics. ${ }^{18,22}$

In the case of microfluidic devices, the latest progress in the field brought cancer research a step closer to the reality of what could happen within a human body. Microfluidic devices can be designed to exhibit structures and complex systems at physiological lengths scales, to incorporate controlled fluid flow, biosensors, and mechanical stimulus, and to control the chemical environment. ${ }^{23,24}$ Besides, microfluidic devices allow studying cancer complexity at a very small scale, with a reduced amount of reagents or biological samples (e.g. blood) and lower costs associated. $^{25}$

In light of the aforementioned, new approaches, consisting of gathering nanoparticles and microfluidic devices, are being proposed and generating great excitement among scientists. ${ }^{26,27}$ This match between nanoparticles and microfluidics have been allowing to respond to cancer challenges as pictured in Figure 1: (i) observation of the influence of natural barriers in nanoparticles transport ${ }^{28-31}$; (ii) real-time monitoring of $\mathrm{CTCs}^{32}$; and (iii) validation of new nanoparticles before testing in in vivo scenarios. ${ }^{33}$

Herein, the recent reports dealing with the simultaneous use of nanoparticles and microfluidic devices to capture CTCs and envisaging the detection of very small changes on biomarker levels in a precise manner are overviewed. Additionally, the development of point-of-care devices to obtain a method for early diagnosis is discussed. Finally, the use of nanoparticles and microfluidic devices to improve therapies are also discussed in depth.

\section{CTCs capture platforms}

The development of non-invasive methods for early cancer diagnosis is one of the main targets that could improve survival rates. CTCs are cells that migrate from the primary tumour into blood circulation, homing in distant organs and initiating the formation of metastasis. Due to this behaviour, CTCs have been emerging as the focus in the development of new diagnostic techniques. In fact, one can envisage the use of CTCs for timely diagnosis; prognosis of clinical outcomes; and prediction of therapies efficiency. Nevertheless, its low concentration in blood circulation, as low as a few hundred cells per $1 \mathrm{~mL}$ of blood, has been hampering its detection and isolation, and consequently its use. Due to these limitations, different strategies have been proposed to capture CTCs, as epithelial cancer biomarker (EpCAM)-based strategies and nucleic acid-based strategies, which will be further discussed. ${ }^{34-36}$ It is important to mention that besides capture, CTCs can be detected by the expression of other biomarkers, such as cytokeratins, epithelial proteins or mesenchymal proteins, ${ }^{37}$ as discussed in section 3. Biomarker detection platforms.

\section{EpCAM-based strategies}

Several approaches have been tested to capture CTCs, as EpCAM-based strategies. Currently, microfluidic devices associated with nanoparticles had shown to be more efficient to capture CTCs than the only assay commercially available, which is designed for CTCs of epithelial origin, CELLSEARCH ${ }^{\circledR C T C}$ Test $\left(\mathrm{CD}^{-} 5^{-}, \mathrm{EpCAM}^{+}\right.$, and cytokeratins $8,18^{+}$, and/or $\left.19^{+}\right) .{ }^{38}$ The modification of nanoparticles with anti-EpCAM antibodies followed by its immobilization into microfluidic devices seemed to be the starting point of these strategies as reported, for example, by Zhao's group. ${ }^{34}$ They described the development of anti-EpCAM modified Titanium dioxide $\left(\mathrm{TiO}_{2}\right)$ nanoparticles immobilized into a glass substrate of a microfluidic device to capture CTCs and allow their visualization under a microscope. But it was the possibility to recover the cells after capture that allowed deepening the knowledge concerning CTCs. In fact, CTCs heterogeneity is one of the main hurdles of cancer therapy. After release from the primary tumour, CTCs can suffer mutation and give rise to new phenotypes. For so, the new chemotherapies developed can lose efficiency once administered in cancer patients. ${ }^{4}$ One possible reason for CTCs develop heterogenic profiles is the fact that they can suffer epithelial-mesenchymal transition. This transition can also be responsible for the loss of the marker EpCAM, decreasing the efficiency of strategies that rely on its presence, ${ }^{39}, 40$ like the commercially available CELLSEARCH®CTC Test.

In this reasoning, two main approaches were followed. In the first, cells were captured by nanoparticles, and then, taking advantage of their electronic features, released upon electric stimulation. ${ }^{41}$ This controlled release promoted under electric stimulation allowed recovering intact cells and the analysis of its gene expression (Figure 2). To validate this system, the authors evaluated the efficiency of cells' capture using different cellular flow rates (Figure 2,B), different cell concentrations and different solutions (Figure 2, C).

On the second, cells were captured by magnetic nanoparticles upon the application of a magnetic field and release when the magnetic field was retrieved, enabling further analysis of captured cells. ${ }^{35,42,43}$ One example was the study of Mohamadi RM and colleagues that developed a platform based on the use of magnetic 


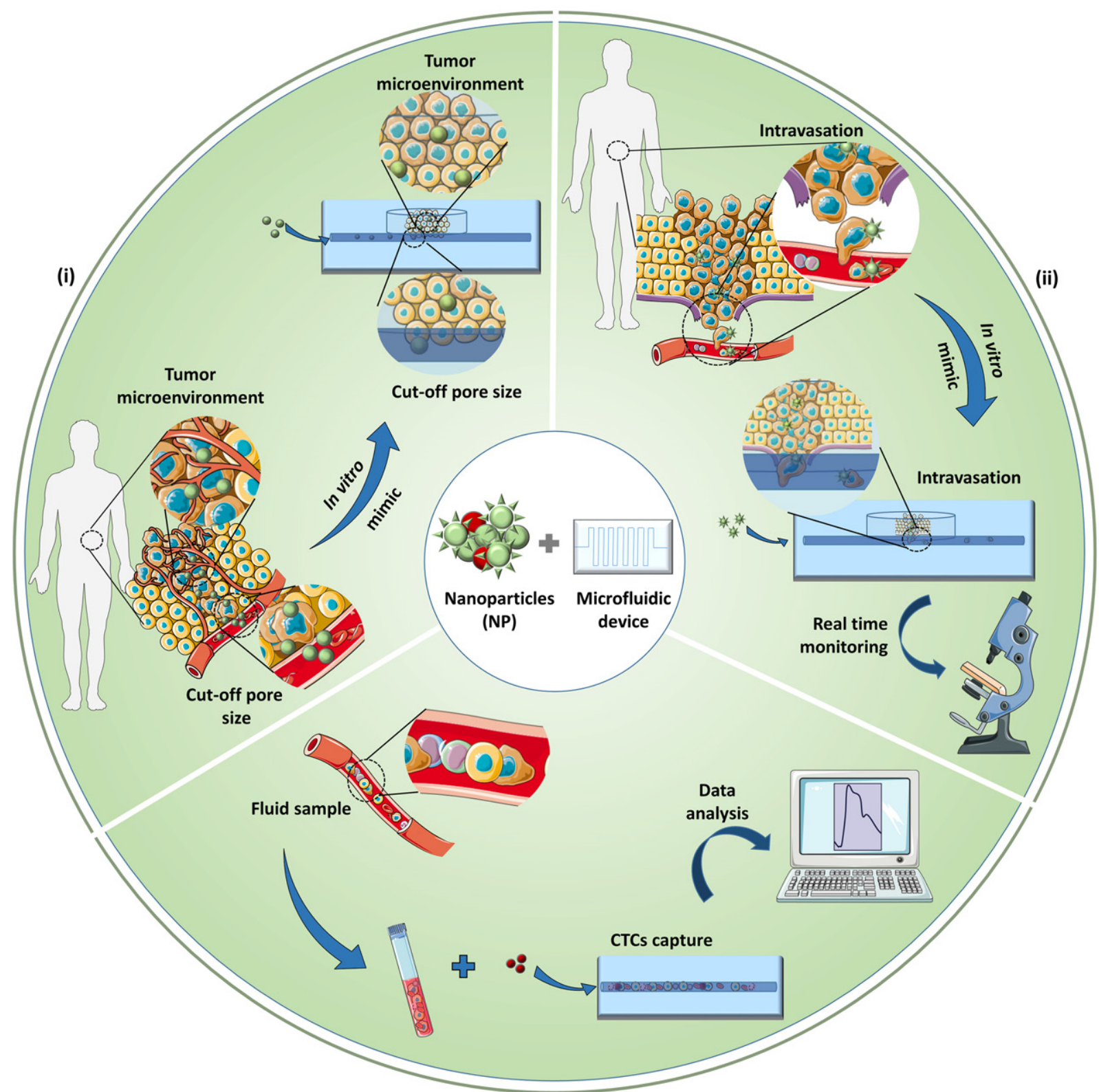

(iii)

- Normal cell Cancer cell (CTCS) Drug modified NP Microfluidic device Fluorescent modified NP Tag modified NP

Figure 1. New and improved approaches generated by the merge of microfluidic devices with nanoparticles (NP) to answer the cancer challenges. (i) Observation of the influence of natural barriers in NP transport, such as tumour microenvironment and cut-off-pore size; (ii) Provide real-time monitoring of cancer cells, such as CTCs migration during intravasation process; and (iii) Validation of new NP before testing in in vivo scenarios such as tag modified NP for the capture of CTCs.

nanoparticles for the CTCs capturing depending on the amount of EpCAM expressed (Figure 3). ${ }^{44}$ Additionally, they also evaluated the EpCAM expression by subjecting cells to different flows inside the microfluidic device (Figure 3,A), separating the different CTCs phenotypes. This method showed higher efficiency than the CELLSEARCH® CTC Test and allowed the visualization and selective recovery of cells. Noteworthy, more recently, the same group published other studies where they showed that cells with low EpCAM expression were related with disease progression since they presented higher collagen uptake and higher metabolic activity, for so, a more invasive behaviour, than cells with higher EpCAM expression (Figure 3, B). ${ }^{45}$ As well, they showed that patients were less responsive to therapy presented low EpCAM expression and high levels of cancer biomarkers, such as androgen receptor variant 7 (ARV7) and the mesenchymal marker, Ncadherin. ${ }^{46}$ 
a
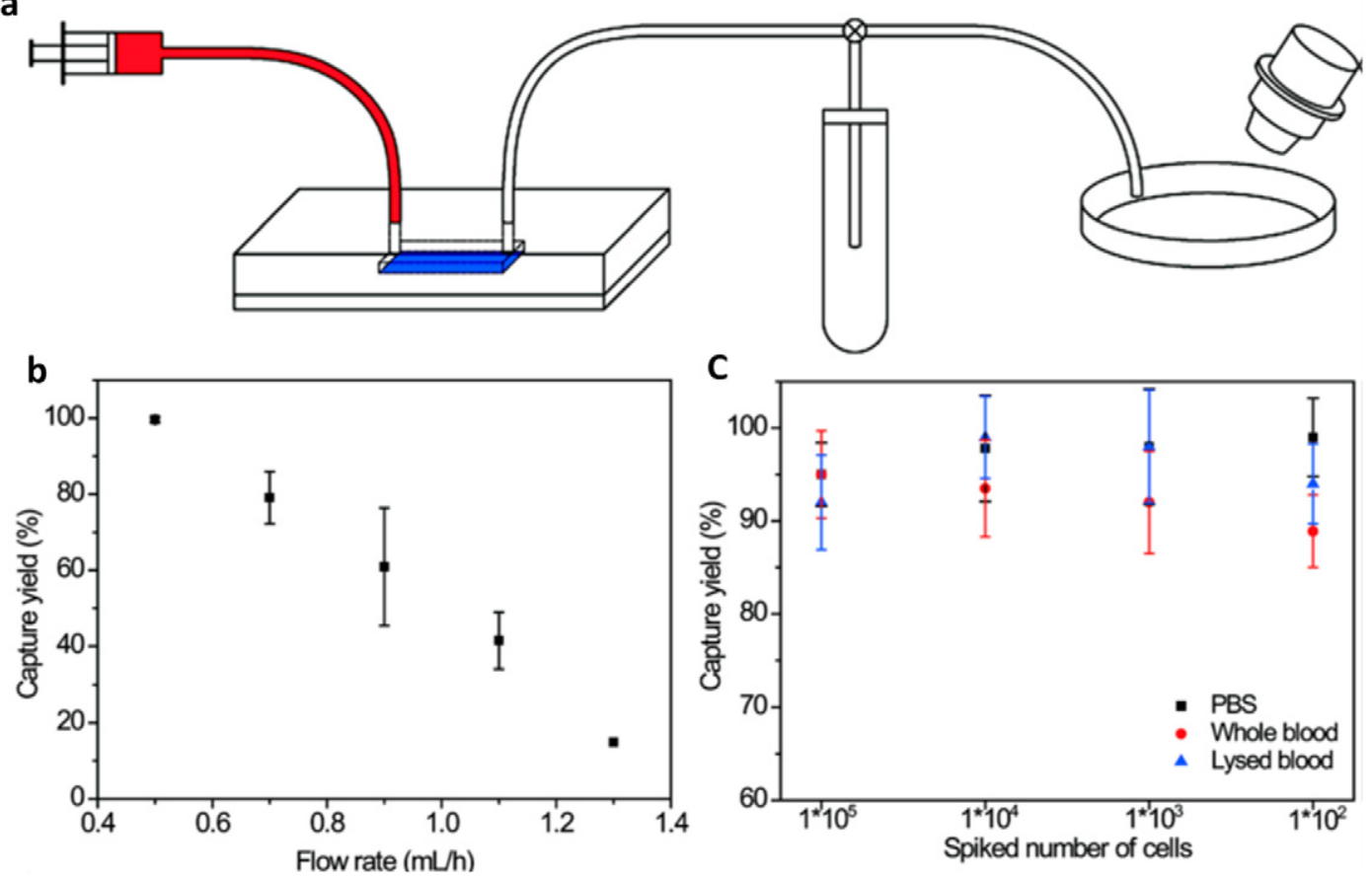

C

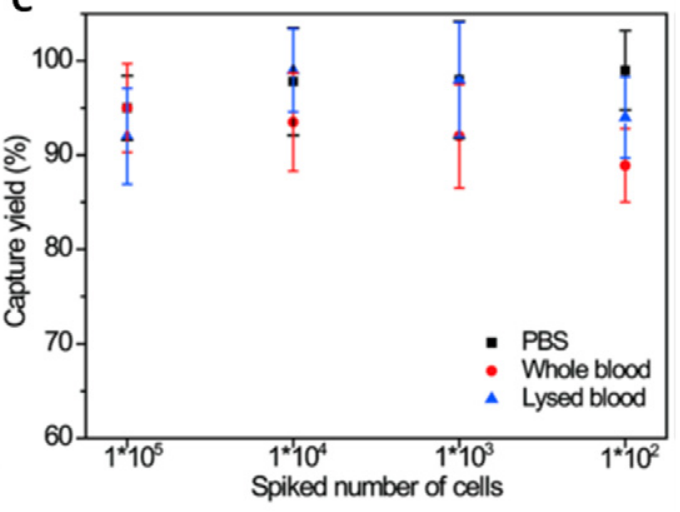

Figure 2. New platform to capture CTCs. (a) Scheme of an electroactive platform capable of capture CTCs and release them upon an induced switch. (b) Efficiency of cell capture at different cell flow rates; and (c) different cell concentrations and solutions. ${ }^{41}$ Copyright $\odot$ 2014, American Chemical Society.

Despite the advance achieved in CTCs capture by using magnetic approaches, some issues still need to be addressed, such as nanoparticle aggregation, and consequently, cell aggregation. To address this limitation, the group of Zhang JXJ developed a new approach with a higher magnetic force based on a micromagnetic-integrated microfluidic system. ${ }^{47}$ The micromagnetic film was patterned into a microchannel where cells tagged with anti-EpCAM magnetic nanoparticles were efficiently trapped, accomplishing a single-cell resolution.

\section{Nucleic acid-based strategies}

Nucleic acid-based strategies have emerged as more efficient than EpCAM based approaches to capture CTCs since it has been shown that CTCs can lose EpCAM expression. For example, the use of DNA probes allowed the detection of low amounts of CTCs in the study performed by Zhang $\mathrm{H}$. and colleagues. ${ }^{35}$ For this, they focused their attention on the presence of carcinoembryonic antigen-related cell adhesion molecule 5 (CEACAM5) mRNA in CTCs. Additionally, they were able to improve the detection sensitivity by amplifying the signal within the microfluidic device by adding horseradish peroxidases and streptavidin to display a fluorescent signal. The new microfluidic sensor showed that it was possible to detect as low as one CTCs per $\mathrm{mL}$ of blood. In a similar approach, Sheng $\mathrm{W}$ and colleagues ${ }^{48}$ developed a strategy based on a multivalent DNA nanosphere to increase the number of captured CTCs. The DNA nanospheres consisted of gold nanoparticles (AuNPs) conjugated with ca. 95 DNA aptamers, which highly increased the recognition capabilities. In fact, with this approach, the authors were able to capture 100 CTCs per $\mathrm{mL}$ of blood. ${ }^{48}$ More recently, Song et al. ${ }^{49}$ modified AuNPs with 250 DNA probes which improved the binding efficiency 100 times compared with studies that used a monovalent aptamer. This approach, presented an advantage since it allowed the release of captured cells upon thiol exchange reaction for further studies.

\section{Biomarker detection platforms}

Although there are several biomarkers associated with different cancer stages, its quantification is still a challenge due to the lack of proper measurement methods. Several technologies have been a motif of study, including enzyme-linked immunosorbent assay (ELISA) for protein biomarkers detection and polymerase chain reaction (PCR) for nucleic acid detection. However, these processes include several steps, resulting in time-consuming methods. To overcome these issues, nanoparticles and microfluidic devices have been used, allowing biomarkers detection in both fluidic and tissue samples.

\section{Fluid samples}

\section{Protein detection and quantification}

Among the approaches tested, different nanoparticles, such as quantum dots, gold and silver NP's, were modified with specific antibodies against different biomarkers known to be associated with cancer (Figure 4). As shown in Table $1,{ }^{50-65}$ several studies have demonstrated different efficiencies regarding detection ranges of single or multiple biomarker detection.

The first nanoparticles, quantum dots (QD), are very attractive nanoparticles for biomarkers detection. This nanosize particles (2-10 nm of diameter) present a semiconductor core that 


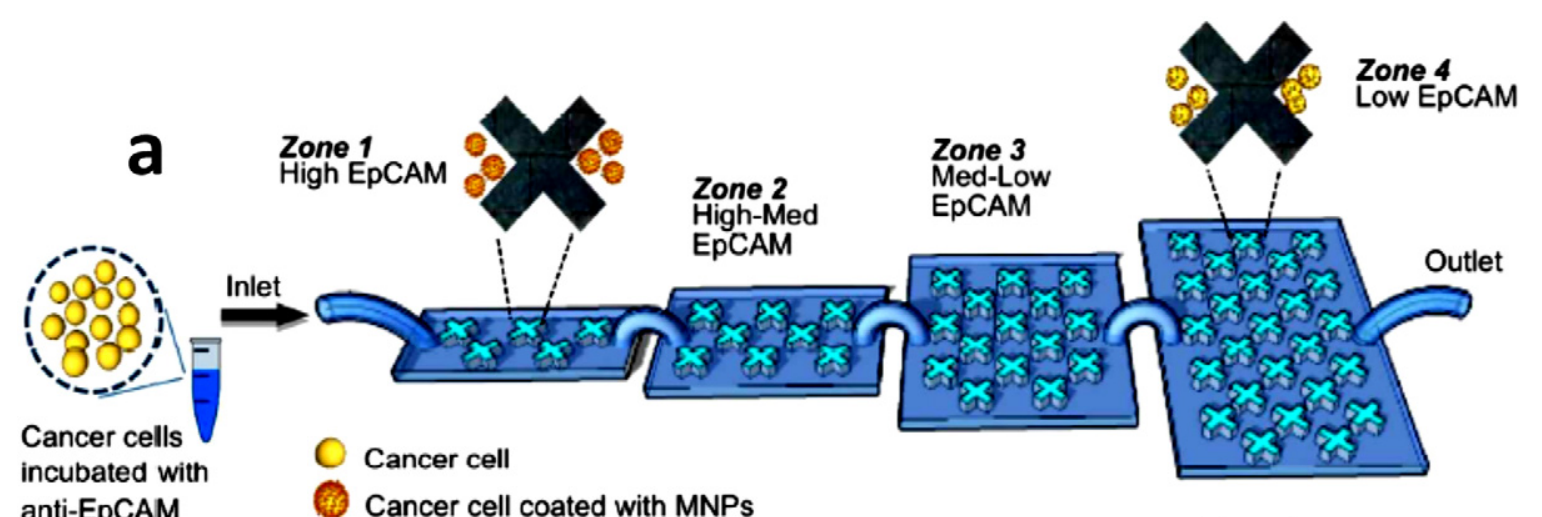
anti-EpCAM MNPS
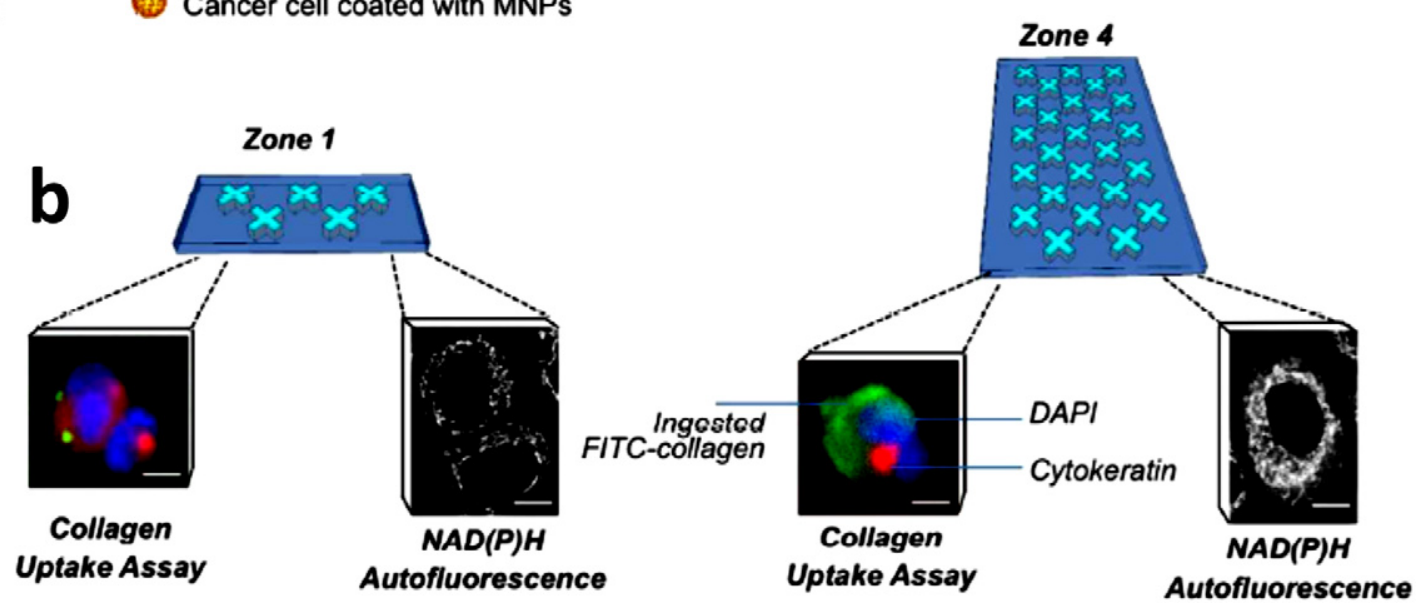

Figure 3. The platform for magnetic separation of CTCs according to their EpCAM expression and their phenotypic profiling. (a) Scheme showing the magnetic separation of CTCs by their EpCAM expression (MNPs - magnetic nanoparticles). (b) Phenotypic analysis of isolated cells showing collagen uptake and metabolic activity by NAD(P)H response. Scale bar: $5 \mathrm{~cm}$. Reprinted with permission from, ${ }^{45}$ Copyright $\odot 2017$ American Chemical Society.

confers very attractive optical properties, such as a broad range of excitation and a narrow emission spectrum that can be finetuned by its size, and a high fluorescence and photostability (Figure 4, A). Altogether, these features potentiate its use in several fields as such as nanodiagnostics and imaging. ${ }^{66}$ For example, the group of Samuel Achilefu immobilized the antiepidermal growth factor receptor (EGFR) antibody, known to be associated with cancer, on the surface of QD. ${ }^{50}$ This way, they showed to be capable to overcome the typical hurdle of the use of fluorochromes for antibodies detection, which is the fluorescence fade away over time. Additionally, they developed a new strategy to immobilize the antibody without losing their binding potential by using click-chemistry technique. With this new strategy, they were able to detect in the range of $\mathrm{ng} / \mathrm{mL}$ of EGFR inside a microfluidic device.

In a different study, $\mathrm{Hu} \mathrm{M}$ and co-workers developed a microfluidic protein device based in a nanoprobe composed of QD modified with anti-carcinoma embryonic antigen (CEA) antibody using DNA as a bridge. ${ }^{51}$ The obtained results were very promising and showed 4 times more sensitivity than QD directly modified without the bridge of DNA. Additionally, they showed that this approach detects as low as $50 \mathrm{fM}$.

Considering gold nanoparticles (AuNPs) and silver nanoparticles (AgNPs), they also present improved features. AuNPs and AgNPs can scatter light intensely and are brighter than fluorophores. ${ }^{67,}{ }^{68}$ Besides, they do not fade away over time, a feature similar to QD. These features promoted their use in the development of more accurate diagnosis tests by improving signal detection (Figure 4, A). For example, Yan J and colleagues have used signal amplification technology based on AuNPs and silver to accomplish higher sensitivity. ${ }^{52}$ First, they immobilized the carcinoma embryonic antigen (CEA) into a microfluidic device, preserving the protein configuration, and used a monoclonal antibody to detect the protein. Then, AuNPs conjugated with secondary antibody were used to recognize the monoclonal antibody. Finally, a silver coating was added to enhance the signal. The results showed a tumour protein chip with the capacity to detect a wide range of concentrations between 5 and $50,000 \mathrm{ng} / \mathrm{mL}$, with a limit of detection of less than $1 \mathrm{pM}$, which is twice the sensitivity of fluorescent-based assays. Moreover, they showed that it was possible to observe the results using a magnifying glass. This interesting improvement demonstrated its feasibility as a point-of-care device. In a more recent work, Giuffrida and colleagues used the AuNPs for signal enhancement. For that, they modified the AuNPs with an aptamer to specifically recognize lysozyme. ${ }^{53}$ That enzyme is known to be overexpressed in leukaemia patients and upon reaction with luminol produced a chemiluminescent signal, which was enhanced by the addition of AuNPs. This method allowed detecting CEA concentrations as low as $44.6 \mathrm{fM}$. 
Single Protein detection

a)

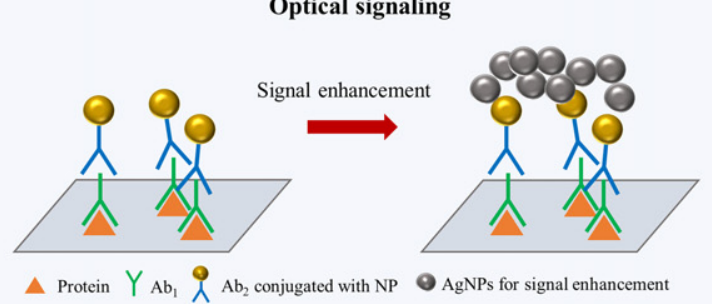

b)

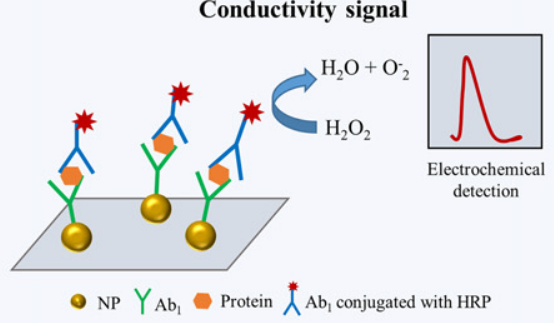

c)

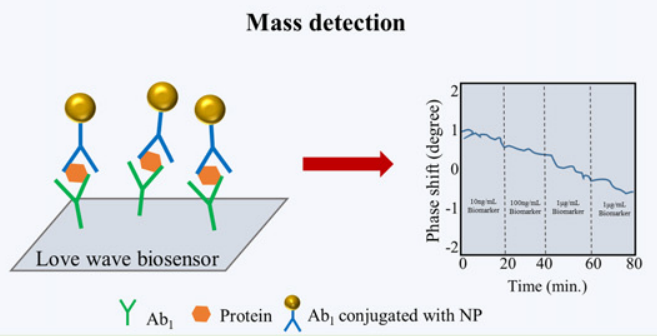

Multiple Protein detection

d)

Optical signaling

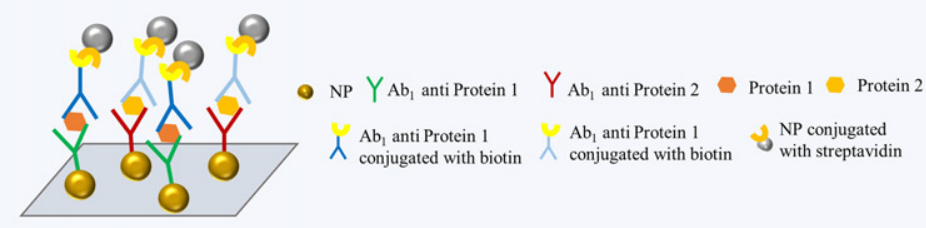

e)

High amounts of HRD

f)
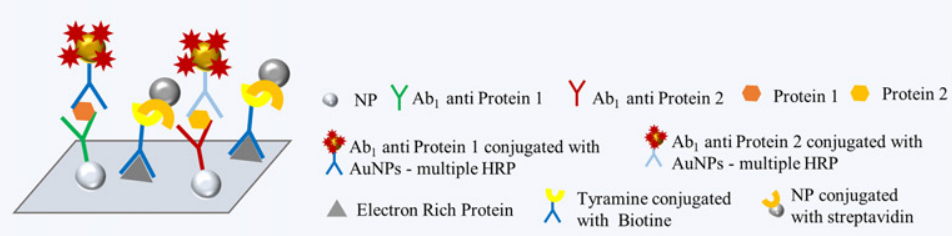

Modified QD

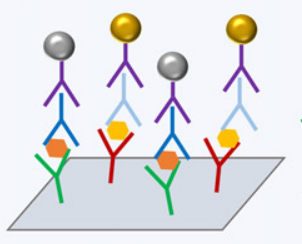

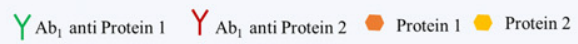

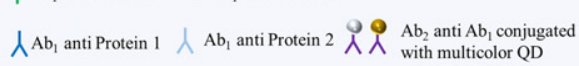

Figure 4. Schematic representation of the use of NP for biomarkers detection. (a) NP can provide an optical signal allowing the detection of biomarkers with no fading of the signal. Additionally, the addition of AgNP promote the enhancement of the optical signal; (b) NP can enhance the signal due to their conductivity properties allowing an electrochemical detection; (c) the mass of NP can be detected by a piezoelectric mass sensor enhancing the signal obtained; (d) NP conjugated with Ab against different protein provide multiple detection by optical signal; (e) The addition of high amounts of HRP and QD allows the enhancement of the signal; (f) The addition of multicolour QD conjugated with Ab against different proteins also allows the enhancement of the signal.

Besides the capability to enhance image signal, AgNPs and AuNPs can also be used due to their high conductivity properties (Figure 4, B) as done by the group of Julio Raba and the group of Sundaram Gunasekarana to detect biomarkers electrochemically. ${ }^{54-56}$ The first group developed a strategy based on the use of AgNPs to detect EpCAM molecules. ${ }^{54,55}$ They used horseradish peroxidase (HRP)-conjugated with a secondary antibody to trap the EpCAM molecule and upon reaction with its enzymatic substrate produced an electric signal proportional to the amount of protein detected. With this strategy, they were able to detect $0.8 \mathrm{pg} / \mathrm{mL}$. In the case of the second group, they developed a strategy to not only detect and quantify proteins but also detect and quantify the cells that presented that molecule. ${ }^{56}$ In this case, they focused on the detection of prostate-specific membrane antigen (PSMA). For that, they used AuNPs modified with anti-PSMA antibody immobilized onto an indium tin oxide (ITO) electrode array. In a further step, they added a redox probe ferricyanide/ ferrocyanide, which upon capture of cells/PSMA, produced a differential pulse voltammetry signal that was detected using an electrochemical workstation. Nevertheless, the limits of detection of this strategy (in the range of $\mathrm{ng} / \mathrm{mL}$ ) were high compared with other strategies. Even so, the fact that this technique can detect cells that present this biomarker ( 150 cell/ $\mathrm{mL}$ ) makes it a promising approach as a targeted therapy.

In a very different approach, AuNPs were used to enhance the signal through the addition of mass (Figure $4, C$ ) ${ }^{57}$ In fact, in this example, the detection of proteins was obtained by a guided shear horizontal surface acoustic wave (SAW) biosensor, termed Love wave biosensor. This sensor is a piezoelectric mass sensor, which can detect small differences in mass on its surface, but at a higher sensitivity than other sensors, as for example quartz crystal microbalances. Finally, to enhance the signal, the authors added AuNPs to this biosensing platform. This strategy consisted of the immobilization of antibodies anti-CEA on the SAW sensor surface, where the CEA would interact and create a difference in mass measurement. On top of that, AuNPs modified with antiCEA antibodies were added to enhance the mass loading effect and consequently enhance the signal. With this combination, researchers produced a small device, with a high sensitivity in the range of $\mathrm{pg} / \mathrm{mL}$, and at low cost, which makes it very attractive to possible point-of-care strategies. 
Table 1

Microfluidic devices and nanoparticles for biomarker detection in fluidic samples.

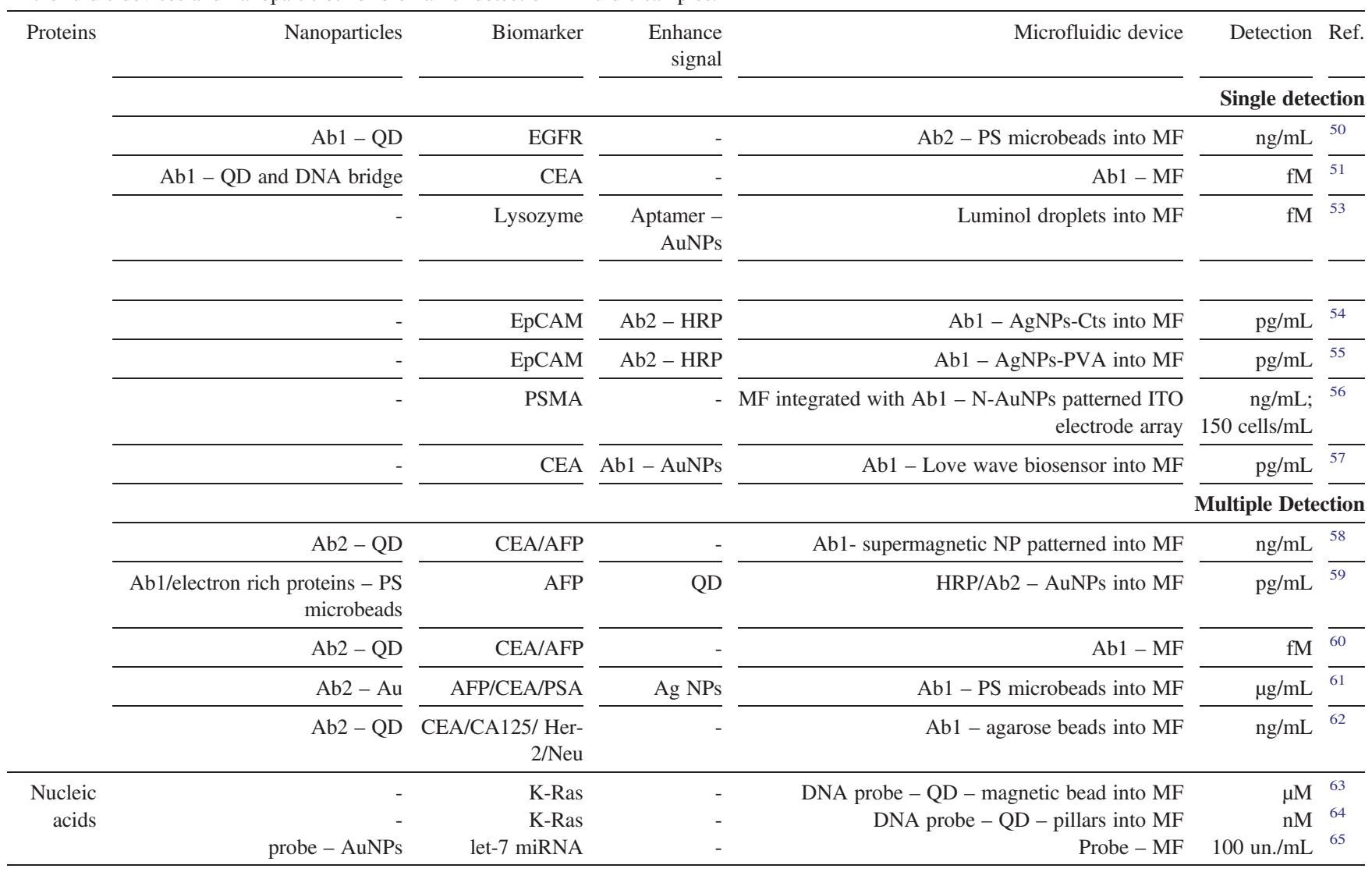

Ab1 - primary antibody; QD - Quantum Dots; EGFR - Epidermal growth factor receptor; Ab2 - secondary antibody; PS - polystyrene; MF - microfluidic device; CEA - carcinoma embryonic antigen; AuNPs - gold nanoparticles; EpCAM - epithelial cell adhesion molecule; HRP - horseradish peroxidase; AgNPs - silver nanoparticles; Cts - chitosan; PVA - polyvinyl alcohol; PSMA - prostate specific membrane antigen; N-AuNPs - N-cysteamine capped gold nanoparticles; ITO - indium tin oxide; Love - guided shear horizontal surface acoustic wave biosensor; AFP - $\alpha$-fetoprotein; NP - nanoparticles; Au - gold; PSA - prostate specific antigen; CA125 - cancer antigen 125; Her-2/Neu - Human Epidermal growth factor Receptor 2; K-Ras - Kirsten rat sarcoma viral oncogene; let-7 - lethal-7; miRNAs - microRNA.

Despite the great results and the potential demonstrated with single biomarker detection strategies for the development of new diagnostic tools, the detection of several biomarkers have been playing an important role in the achievement of more reliable diagnostic tools (Figure 4,D). For example, Yu X and colleagues developed a microfluidic with patterned super magnetic nanoparticles and QD to detect simultaneously two molecules, CEA and AFP. ${ }^{58}$ The super magnetic nanoparticles were modified with dedicated antibodies to capture the biomarkers, while the QD were used for fluorescence display, allowing the quantification of biomarkers' concentration. The method allowed the detection of CEA and AFP in the range of $\mathrm{ng} / \mathrm{mL}$, which was higher than the efficiency obtained with single protein detection. For so, scientists have pursued other approaches to increase the sensitivity, which were based on the addition of high amounts of horseradish peroxidase that allowed the bonding of high amounts of QD, or just in the modification of QD for signal enhancement (Figure 4, $E$ and $F$, respectively). In the first case, the addition of horseradish peroxidases, Zhu group, showed to increase the detection limit 500 times when compared with traditional methods, and 50 times when compared with microfluidic device based methods, detecting in the range of previous study i.e. pg/ $\mathrm{mL} .{ }^{59}$ In the second case, the modification of QD, Hu et al. ${ }^{60}$ showed that by modifying them with secondary antibodies it was possible to obtain a multicolour fluorescent signal amplifier probe, achieving a detection limit similar to single protein detection methods. The results showed that the modified QD improved the detection limit of a mixture of CEA and AFP to as low as $250 \mathrm{fM}$. Noteworthy, this value corresponds up to four times higher sensitivity when compared with organic dyes.

Ko et al. ${ }^{61}$ and Jokerst et al. ${ }^{62}$ had pursued as well the development of a more trustworthy test by increasing the number of biomarkers simultaneously detected. Despite their work not being as recent as the works presented here, nor as sensitive, it is worth mentioning. Their work was one of the first works involving the detection of several biomarkers simultaneously. The study of Ko et al. ${ }^{61}$ reported an electro-immunosensing structure to detect simultaneously three cancer biomarkers $(\alpha-$ fetoprotein (AFP), CEA and PSA), in real-time. For that, they immobilized polystyrene microbeads modified with antibodies against the biomarkers into a microfluidic device. Then, the authors used a coating of gold conjugated with a second antibody 
a
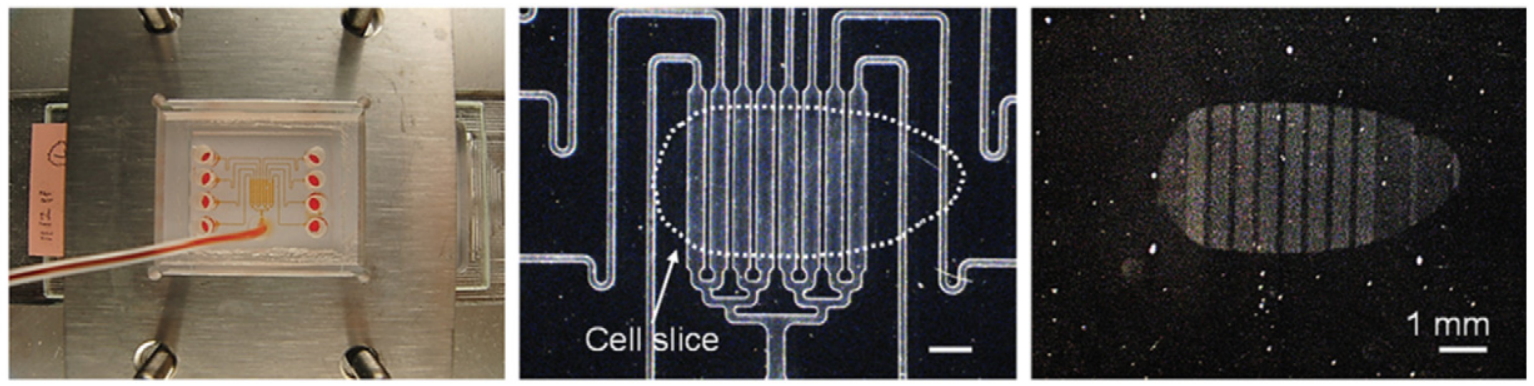

b

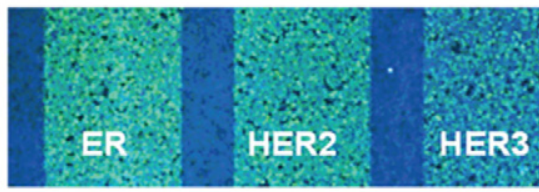

C
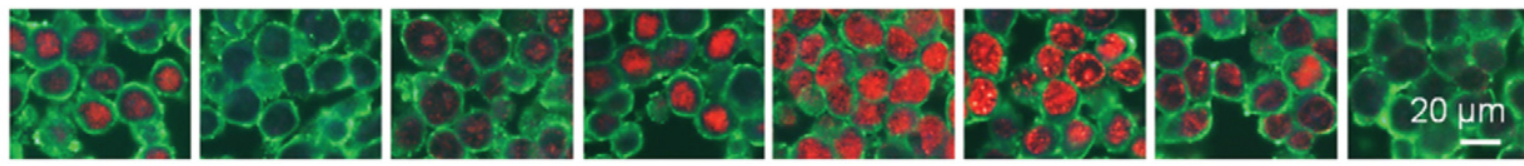

Figure 5. QD based microfluidic device used to quantify the expression of proteins of tissue samples. (a) Example of a microfluidic device to quantify the expression of proteins at a single-cell level. The microfluidic device (left) is placed on the cell-block section (center), then, upon immunoreactions, the microfluidic device is detached from the cell-block section (right). (b) Analysis of eight different proteins using the microfluidic immunostaining system. (c) Magnified images of detected areas, as labelled in B. ${ }^{72}$ Copyright $\odot 2014$, Royal Society of Chemistry.

to detect the biomarkers. Finally, they used silver staining to enhance the electrical signal. The results demonstrated the detection in the range of $\mu \mathrm{g} / \mathrm{mL}$. Concerning the second study, Jokerst et al. ${ }^{62}$ integrated QD labelled with antibodies, for CEA, CA125 and Human Epidermal growth factor Receptor 2 (Her-2/ $\mathrm{Neu}$ ) detection, and agarose beads, for antigen capture, into a microfluidic device. With this approach, the authors were capable to detect concentrations two times lower in comparison with ELISA assays, which were higher compared with new advances discussed above.

\section{Nucleic acids detection}

Since 1977, nucleic acids present in circulation have been reported in cancer patients. Additionally, it was observed different amounts of nucleic acids according to the stage of cancer or treatment administered. ${ }^{69}$ Later on, the presence of nucleic acids was correlated with the malignancy of cancer. ${ }^{70}$ However, it was only in 1994 that mutated molecules that lead to countless genetic and epigenetic studies to detect anomalies in cancer patients were reported. ${ }^{71}$ After this, nucleic acids began to be studied as a diagnosis approach, similar to what happens in protein detection. For this, QD have been used instead of conventional fluorophores due to its optical properties as happened for protein detection. Nevertheless, the sensitivity values obtained for nucleic acids-based biomarkers are still very high as compared with protein-based biomarkers detection (Table 1). For example, in the work of Noh HN and Kim JS, they have shown that it was possible to detect $\mu \mathrm{M}$ of oncogene, K-Ras, through hybridization with a DNA probe coupled to the QD. ${ }^{63}$ The QD were linked to a magnetic bead for support inside of a microfluidic device. Upon interaction with target DNA, the fluorescence of QD was quenched by an intercalating dye. This way they obtained a rapid and efficient way to detect, by fluorescence quenching, in a few minutes in a microfluidic device. More recently, the same group continued its studies concerning the detection of K-Ras through quenching QD fluorescence. ${ }^{64}$ However, this time the QD were not immobilized through magnetic beads. The author's produced pillars inside the microfluidic device aiming to trap the QD. Additionally, they developed a microfluidic chip with two microchannels, enabling the simultaneous detection of the N-Ras gene and its three nucleotides substituted mutated gene. Interestingly, the results showed that they were able to lower the concentration of DNA to $5 \mathrm{nM}$ and even so, discriminate both genes.

Other nucleic acids widely studied are the microRNAs (miRNAs). The miRNAs, a highly conserved noncoding 22 nucleotides that can control gene expression, are involved in cancer progression which makes them attractive as cancer biomarkers. Nevertheless, nowadays they are detected through immunofluorescent based multiple steps protocols that are too time-consuming. To overcome this, nanoparticles have been used, improving not only the reaction time but also the sensitivity, as shown by Roy $\mathrm{S}$ and colleagues. ${ }^{65}$ They developed a device for lethal 7 (let-7) miRNA detection without any labelling and amplification steps. In this sense, they used a microfluidic device for probe immobilization, which hybridizes with the entire length of target miRNA. Then, the unhybridized probes were removed and a signalling probe with AuNPs was allowed to interact with the remains probes. These interactions gave a direct quantification of the number of miRNA detected through differential interference contrast microscopy. This technique allowed the detection of just a few hundred copies of miRNA present in microliters of sample and the discrimination of other miRNA that differ only in few nucleotides. 

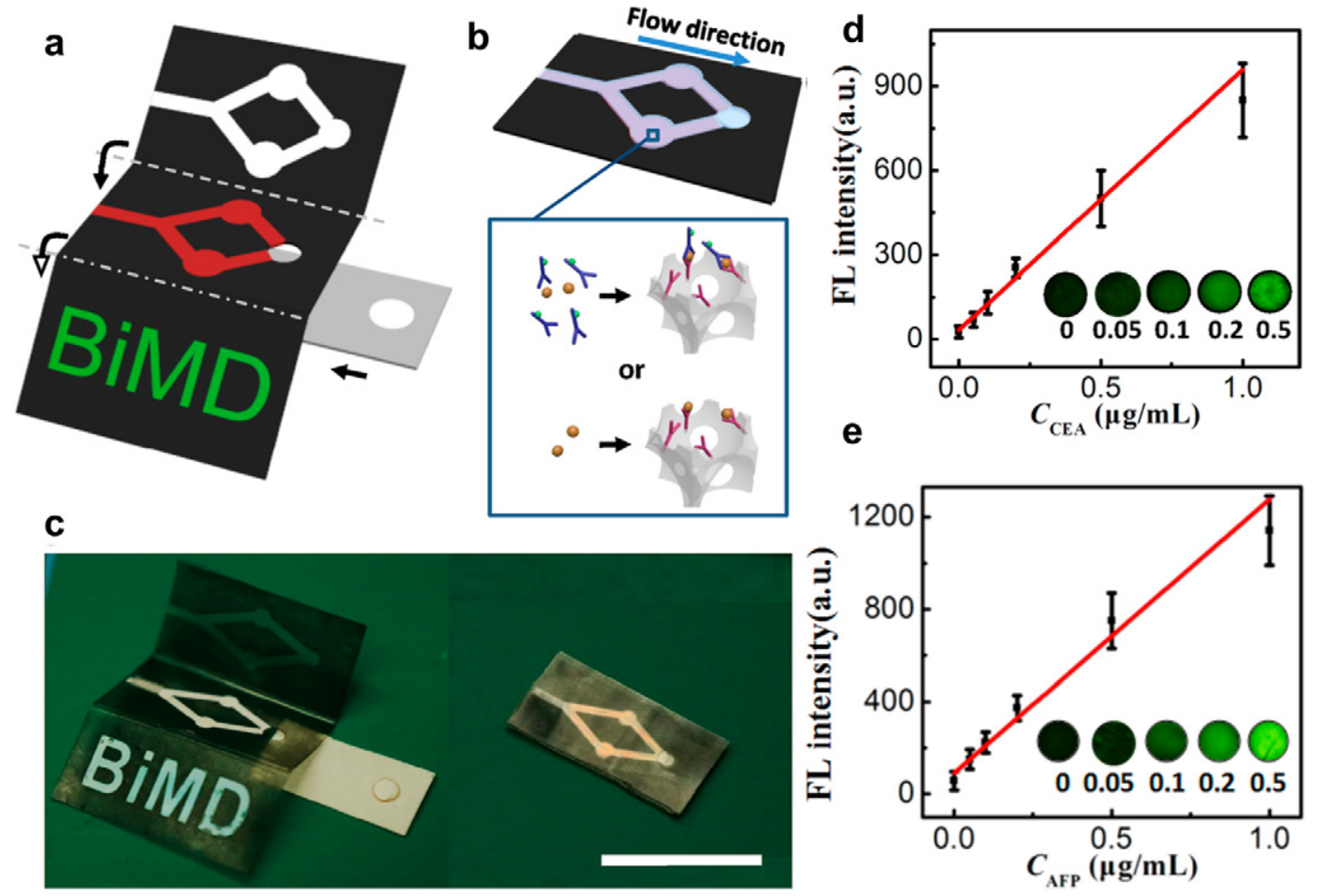

Figure 6. Portable point-of-care was capable to detect, quick and easily, specific biomarkers. Scheme of a portable point-of-care showing (a) the unfolded form, and (b) the fluorescent and label-free detection approaches. (c) Image of the portable point-of-care before and after assembly. Scale bar: $2 \mathrm{~cm}$. (d) Fluorescent intensity of the detection reservoir of the portable point-of-care as a function of CEA concentration (CCEA). (e) Fluorescent intensity of the detection reservoir of the portable point-of-care as a function of AFP concentration (CAFP), ${ }^{86}$ Copyright @ 2016, American Chemical Society.

\section{Tissue samples}

Besides fluids, tissues from cancer patients can also be analysed (Figure 5). The molecular profiling of cancer cells can give priceless information to personalize therapeutics. Sensitive quantification methods capable to detect multiple molecules at a single cell level can boost precise cancer diagnosis, as demonstrated by Kwon $\mathrm{S}$ and colleagues. ${ }^{72}$ They used a QD based microfluidic device to quantify the expression of proteins at a single cell level through immunochemical assays and using a control protein, $\beta$-actin, as an internal reference. For that, they inserted a microfluidic device on top of tissue samples and injected QD labelled with antibodies as depicted in Figure 5, A. After, fluorescence intensity was measured and normalized with the internal reference. This method allowed the determination of the expression of eight different proteins in the same sample (epidermal growth factor receptor 2 (HER2), Ki-67, Estrogen receptor (ER), progesterone receptor (PR), mammalian target of rapamycin (mTOR), transforming growth factor-alpha (TGF- $\alpha$ ), betacellulin (BTC) and HER3) (Figure 5, $B$ and $C$ ). In a different approach to detect and quantify multiple biomarkers, the group of Park JK developed a method also based on QD. This time they used cytokeratin as protein reference, which allowed not only to normalize the values but also to remove the autofluorescence. ${ }^{73}$ They used breast cancer tissue' sections, to compare with conventional scoring methods and labelled cytokeratin, to detect cancer area. First, they aligned a microfluidic chip on top of the cancer tissue samples. Then, they used QD with antibodies to detect and quantify three different biomarkers, ER, PR, and HER2, into each respective microchannel. That technique correlates with conventional methods and provides accurate measurements. Besides the obvious advantage of allowing the determination of different proteins simultaneously, these methods hold great promise for the detection of small differences between patients. In this sense, it would allow obtaining a more accurate diagnosis and distinguish between different outcomes, resulting in the administration of more personalized therapies.

\section{Portable point-of-care devices}

The development of portable point-of-care devices is important for the detection of specific biomarkers on-demand, and quickly and easily, supporting clinical decisions (Figure 6). Most of the portable point-of-care devices developed were microfluidic paper-based devices established for electrochemical signals detection. ${ }^{74,75}$ Paper has several advantages, such as do not involve any external devices for fluidic transportation, since it occurs via capillary action; involves small volumes; is easy to transport and store, and they are disposable. With these in mind, Wang et al. ${ }^{76}$ developed a three-dimensional microfluidic paperbased device, utilizing biocatalysts. For that, they patterned a layer of AuNPs on the surface of the paper with capture antibodies for CEA. Then, a glucose-air enzymatic biofuel cell was used to self-power the device. This way, the authors were capable to quantify the bioelectrocatalytic activity caused by the 
addition of a glucose dehydrogenase load secondary antibody. The results showed to be proportional to the amount of CEA capture with a wide linear range and low detection limit of pg/ mL. Recently, Bahavarnia et al. ${ }^{77}$ developed a more sensitive paper-based platform for the electrochemical detection CA 125 reaching values as low as $0.78 \mathrm{U} / \mathrm{mL}$ in human plasma samples. $\mathrm{Wu} \mathrm{Y}$ and colleagues also pursued a microfluidic paper-based approach to detect multiple biomarkers (AFP, CEA, CA125 and carbohydrate antigen 153 (CA153)). ${ }^{78}$ The developed analytical device used a graphene layer and a co-immobilization of HRP and antibody on silica nanoparticles, for detection and amplification of electrochemical signals. This way, they were capable to achieve a limit in the range of $\mathrm{pg} / \mathrm{mL}$. More recently, Wang et al. ${ }^{75}$ developed a paper-based sensor for the detection of CEA and neuron-specific enolase (NSE) based on the electrochemical features of AuNPs and Prussian Blue with similar detection limits.

Interestingly, Fan et al. ${ }^{79}$ studied the development of a pointof-care device for on-site detection through an electrochemical detector and an Android smartphone. First, amino-functional graphene $\left(\mathrm{NH}_{2}-\mathrm{G}\right)$ was modified with thionine (Thi) and with AuNPs, to amplify the signal and provide conductivity. Upon reaction of capture NSE with AuNPs, an electrochemical detector measured the differential pulse voltammetry, which was then, visualized by the Android's smartphone. This strategy was capable of identify $\mathrm{pg} / \mathrm{mL}$ of NSE, and together with its low cost of production makes this a very competitive approach for point-of-care devices.

In a different approach, more user-friendly point-of-care devices were developed based on colorimetric detection. ${ }^{80-84}$ For example, Hu SW and colleagues ${ }^{80}$ developed a hydrophilic device where droplets with magnetic nanoparticles modified with antibodies specific for CEA were obtained. To detect the biomarker, the authors used horseradish peroxidase modified with an antibody to allow a 3, 5, 3', 5'-tetramethylbenzidine (TMB) -based colorimetric detection. This way, they were able to detect $\mu \mathrm{g} / \mathrm{mL}$ of the biomarker in 2 hours, relying only on liquid dispensation. In a different study, Wu MS and colleagues also pursued the development of a microfluidic device for visual quantitative detection of several biomarkers, simultaneously. ${ }^{81}$ The microfluidic device was composed of one channel to detect and another to sense the different biomarkers tested (adenosine triphosphate (ATP), PSA, AFP, and thrombin). For that, they used biorecognition elements (aptamers or antibodies), and an electrochemical tag (thionine) immobilized in silica nanoparticles. These silica nanoparticles activated the electrochemiluminescence reaction when connected to the biomarker, producing a visual outcome in 50 seconds. Additionally, the colour developed was directly proportional to the concentration of biomarkers and allowed to detect concentrations in the fM range. More recently, QD were used to obtain a device with fluorometric determination capacities. ${ }^{85}$ For this, the authors modified QD with different fluorescent emission peaks to detect CEA and PSA molecules simultaneously in the range of $\mathrm{ng} / \mathrm{mL}$.

Nevertheless, these paper-based microfluidics devices present some problems that need to be addressed. On one hand, the irregularity of paper hampers the production of small micro- channels, as the ones achieved with other materials. On the other hand, its fibres are not uniformly distributed which influences the flow profile and flow rate, resulting in low reproducibility and increases the time of analysis. To overcome those limitations, Gao et al. ${ }^{86}$ developed a patterned photonic nitrocellulose based microfluidic device (Figure 6), pictured in the unfold form and after assembly in Figures 5, $A$ and $C$, respectively. First, they placed $\mathrm{SiO}_{2}$ nanoparticles into the microchannel template and then they filled it with the nitrocellulose. After that, they removed the nanoparticles and end up with an organized structure of nitrocellulose. This technique allowed the production of microchannels with $10 \mu \mathrm{m}$ of width and consequently the reduction of reagents needed for the analysis. Additionally, it allowed the detection of biomarkers through two different approaches, fluorescent, and label-free (Figure 6, $B$ ). To validate this new designed microfluidic device, the authors analysed CEA (Figure 6,D) and AFP (Figure 6, E). For that, they immobilized antibodies against these biomarkers to trap them and used secondary antibodies, fluorescently labelled, to detect them. Despite the evident advantages of such types of microfluidic devices, the concentrations detected were quite high, $0.021 \mu \mathrm{g} /$ $\mathrm{mL}$ for CEA and $0.032 \mu \mathrm{g} / \mathrm{mL}$ for AFP.

Later on, Kadimisetty and colleagues pursued the development of 3D-printed microfluidic devices capable of measuring several proteins simultaneously also using electrochemiluminescent technique. ${ }^{87,88}$ The first designs were able to detect up to three molecules (PSA, PSMA, and PF-4) and as low as 300-500 fg/mL in less than $1 \mathrm{~h}(\approx 35 \mathrm{~min}) .{ }^{87}$ But in the last studies the authors added an automated micro-pump integrated within the device, enabling the detection of eight biomarker proteins (Insulin-like growth factor 1 (IGF-1); PSA; PF-4; cluster of differentiation 14 (CD-14); Vascular endothelial growth factor D (VEGF-D); Golgi membrane protein 1 (GOLM1); PSMA; Insulin-like growth factorbinding protein 3 (IGFBP-3)) in human serum in less amount of time $\left(\approx 25 \mathrm{~min}\right.$.) with a detection limit of $85-110 \mathrm{fg} / \mathrm{mL} .{ }^{88}$ The main advantage of the system is not the efficiency, sensitivity, not even the detection limits, but its low cost $(\approx \$ 1.10)$ and the low amounts of reagent needed $(\approx 50 \mu \mathrm{L})$, making this device a promising point-of-care. In fact, besides the fast and easy detection of biomarkers on-demand, point-of-care devices should fulfil other requisite, they should present low costs to be suited for the clinic, including in low resources environments. Nuno M. Reis evaluated two different procedures for optical detection of PSA on a transparent plastic microcapillary film (MCF). ${ }^{89}$ One was based on carbon nanoparticles, while the other was based on AuNPs. In the case of carbon nanoparticles, MCF was coated with a biotinylated antibody, which then reacted with the neutravidin conjugated carbon nanoparticle, resulting in an optical colorimetric signal. In the case of AuNPs, the procedure was longer. First, the MCF was coated with anti-PSA antibody, then, PSA was added and AuNPs modified with anti-PSA were allowed to react and detect it. Finally, to enhance PSA detection, AgNPs were added, resulting in an optical colorimetric signal, as well. To image both procedures' results, a flatbed scanner in transmittance mode was used. Although, they obtained low levels of sensitivity, $\mathrm{ng} / \mathrm{mL}$, in the case of AuNPs, and $\mu \mathrm{g} / \mathrm{mL}$, in the case of carbon nanoparticles, the authors demonstrated the feasibility to produce an optical point-ofcare based on nanoparticles immunoassay labelling. 
Table 2

FDA approval of new drugs during the first semester of 2019, taken from Hematology/Oncology (Cancer) Approvals \& Safety Notifications. ${ }^{90}$

\begin{tabular}{lllll}
\hline Drug & Commercial name & Company & Type of cancer & Molecule of interaction \\
\hline Pexidartinib & TURALIOTM & Daiichi Sankyo & Tenosynovial giant cell tumor & CSF1 receptor \\
Darolutamide & NUBEQA & Bayer HealthCare Pharmaceuticals Inc. & Prostate cancer & Androgen-receptor \\
Selinexor & XPOVIO & Karyopharm Therapeutics & Multiple myeloma & CRM1 \\
Polatuzumab vedotin-piiq & POLIVY & Genentech, Inc. & Diffuse large B-cell lymphoma & CD79b \\
Alpelisib & PIQRAY & Novartis Pharmaceuticals Corporation & Breast cancer & PI3K \\
Erdafitinib & BALVERSA & Janssen Pharmaceutical Companies & Urothelial carcinoma & FGFR \\
Trastuzumab and hyaluronidase-oysk & Herceptin Hylecta & Genentech Inc. & Breast cancer & HER2 \\
\hline
\end{tabular}

CSF1- Colony Stimulating Factor 1; CRM1- Chromosome Region Maintenance 1; CD79b - Cluster of Differentiation 79b; PI3K - Phosphoinositide 3 Kinase; FGFR - Fibroblast Growth Factor Receptor; HER2 - Human epidermal growth factor receptor 2;

\section{Microfluidic devices and nanoparticles for therapies' improvement}

Currently, therapies have shown different efficiencies within the same tumour, hindering its approval by the Food and Drug Administration (FDA), and thus, its translation into clinics. In fact, during the first semester of 2019, the FDA approved a very limited amount of new drugs for the treatment of cancer as summarized in Table 2. ${ }^{90}$ That types of drugs were developed based on their interaction with specific molecules with the intent to enhance their efficiency while decreasing any deleterious effect for healthy cells.

One of the reasons for the scarce approval of new therapies is the lack of an in vitro model capable to produce accurate data. In this reasoning, microfluidic devices and nanoparticles have been strategic for the improvement and evaluation of newly designed pharmacotherapies in vitro.

On one hand, microfluidic devices allowed a scale-down of traditional validation systems, such as the assessment of cell death, lowering the amounts of reagents necessary and the time of reaction. Cell death evaluation is usually laborious, timeconsuming and reagent consuming. For example, Zhao et al. ${ }^{91}$ studied a drug screening platform composed of a microfluidic device and a nanoapoptotic probe. The nanoapoptotic probe consisted of QD conjugated with Annexin-V, to detect phosphatidylserine (a marker of apoptosis). These nanoprobes interacted with apoptotic cells, revealing the efficacy of each drug.

On the other hand, microfluidic devices can be designed to offer a scenario that is as physiologically relevant as possible, when compared with the typical in vitro two-dimensional (2D) settings. A model that can replicate more closely the real environment, can provide more accurate data as demonstrated by Carvalho et al.. ${ }^{92}$ In this reasoning, several studies were performed taking in consideration this feature to obtain more reliable data concerning therapies assessment, such as photodynamic therapy, ${ }^{93,} 94$ concerning physiological data, such as the nanoparticles' transport within the tumour environment, ${ }^{95,96}$ or concerning the prediction of the effect of therapies during cancer treatment, such as chemotherapy and radiotherapy. ${ }^{97}$

Furthermore, the use of microfluidic devices and nanoparticles has been crucial for the study of new strategies and to overcome some issues related with the development of efficient therapies, such as the low targeting efficiency, and related with drug delivery, namely the retention observed during systemic administration (Figure 7). For example, nanoparticles can mount up within diseased sites through passive targeting (i.e. due to their inherent EPR effect) and damage healthy cells weakening their therapeutic activity. To overcome these issues, it was proposed the binding of specific ligands to nanoparticles to more precisely target cancer cells (i.e. active targeting). One example is the use of laminin receptors as a target for lung melanoma metastasis by Sarfati and colleagues. ${ }^{98}$ The rational was the high levels of laminin receptors presented by cancer cells and their roles during invasion of host tissues, leading to the production of ten times more metastases. ${ }^{99}$ It is described that the receptors expressed in cancer cells interact with the laminin present on the basement membrane. This interaction, enable the proteolytic degradation of the matrix, and ultimately, the invasion of deeper connective tissues. ${ }^{100}$ During this study, Sarfati and colleagues ${ }^{98}$ assessed the effectiveness of modified nanoparticles uptake by cancer cells in vitro using a microfluidic flow-through system. This system enables the prevention of nanoparticle precipitation and any non-specific adsorption on cells due to the constant flow. Additionally, the flow to which cells were submitted emulated the flow of blood vessels, providing a more realistic environment to the in vivo than standard 2D. Since blood vessels are one of the major "highways" for cancer spreading and metastasis formation, it is possible to predict the enormous advantages of using microfluidic devices for these types of studies as shown by Kolhar and colleagues. ${ }^{101}$ The authors studied intercellular adhesion molecule-1 (ICAM-1) expressed by endothelial cells and associated with aggressive cancers by facilitating their invasion. ${ }^{102,103}$ To screen the efficiency of the modified nanoparticles, researchers injected them intravascularly and at the same time into a microfluidic device. ${ }^{101}$ The effect of nanoparticles' shape, rods or spheres, was also a motif of study, due to their percussions on hydrodynamics. The results reported that rod-shaped particles, with higher aspect ratio, had increased selectivity towards endothelial cells than sphere-shaped particles. This difference improved the specificity of the ligand present in the surface of the nanoparticles, in vitro as well as in vivo, certifying once more the value of the microfluidic devices as an in vitro setting. In a different study, iron-gold ( $\mathrm{Fe}-\mathrm{Au}$ ) nanoparticles modified to target cancer cells underflow, and induce cell death by magnetic hyperthermia coupled to forceinduced signalling pathway hyperactivation were investigated.${ }^{104}$ In this case, the target selected was a receptor tyrosine kinase 

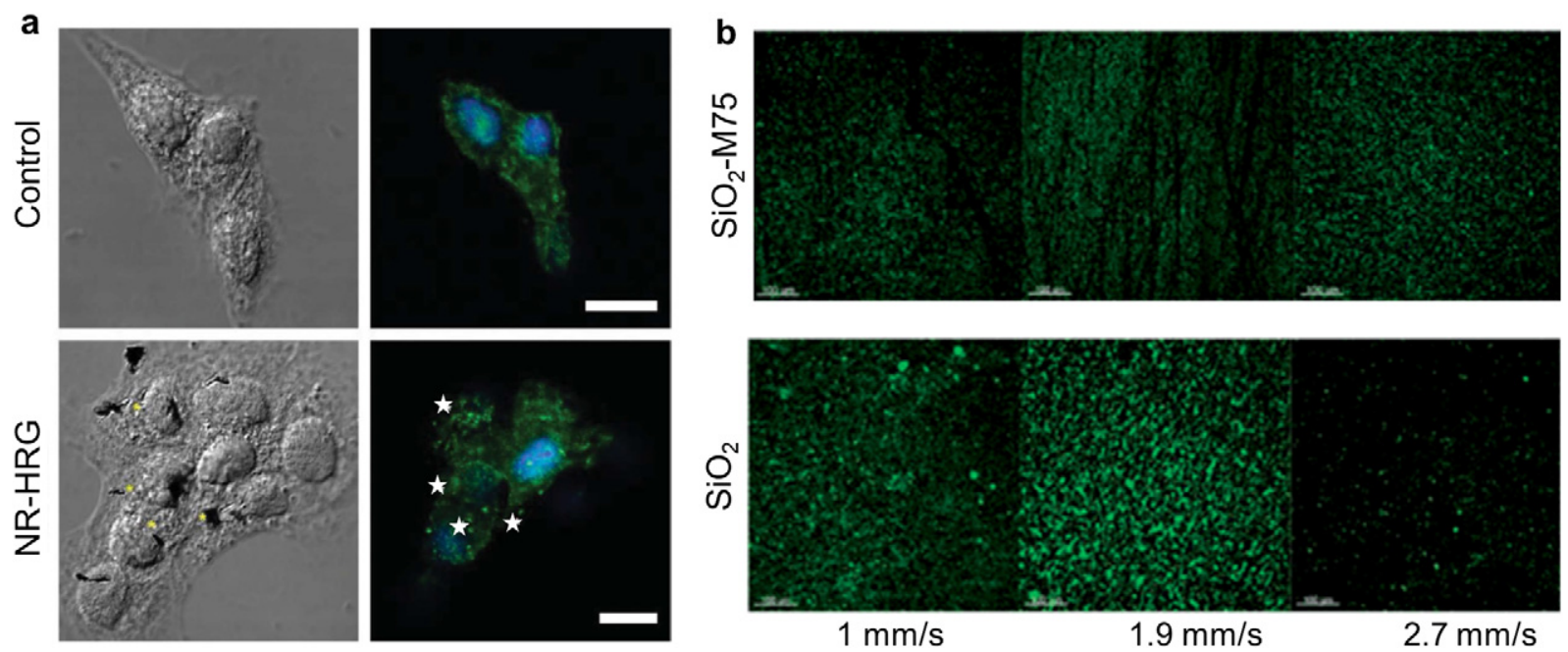

Figure 7. (a) Target of cells using heregulin (HRG)-nanoparticles. Confocal images showing targeted (NR-HRG) and non-targeted (Control) cells (ErbB2 receptors - green and nuclei - blue). Stars indicate examples of ErbB2 receptor clusters. Scale bars: $10 \mu \mathrm{m} .{ }^{104}$ Copyright $@ 2014$ WILEY-VCH Verlag GmbH \& Co. KGaA, Weinheim; (b) Fluorescent microscopy images showing the adhesion strength of modified nanoparticles $\left(\mathrm{SiO}_{2}-\mathrm{M} 75\right)$ and control $\left(\mathrm{SiO}_{2}\right)$ to cells under fluid flow conditions. Scale bar: $100 \mu \mathrm{m} .{ }^{109}$ Copyright $\odot$ C The Royal Society of Chemistry 2013.

(ErbB) ligand, the Heregulin (HRG) (Figure 6, A). ErbB receptors are described to be overexpressed in several types of solid tumour. ${ }^{105}$ The results showed that nanoparticles not only favourably target cancer cells but also induced cell death when stimulated.

Also, the use of microfluidic devices has allowed the improvement of other therapies, as photothermal therapies promoted by plasmonic materials. These materials can produce heat upon near-infrared light exposure. This phenomenon is called surface plasmon resonance (SPR) and occurs due to rapid oscillations in the material's electrons. The use of such characteristics, associated with the fact that those same nanoparticles can be functionalized with drugs of interest, could improve drug delivery efficacy. Nevertheless, tumours have shown to have the capacity to adapt to several adversities, namely thermotolerance, which can be assigned to heat-shock factor-1 (HSF1). This molecule protects cells from damage induced by high temperatures and is activated in tumours. ${ }^{106,107}$ The capability to test in vitro cellular adaptations and understand the pathways behind it can improve largely drug delivery approaches. In this sense, and to understand the repercussion of the activity of this molecule in drug delivery, Bagley and colleagues used a microfluidic device to mimic tumor vasculature. ${ }^{108}$ For that, the authors developed a monolayer of endothelial cells encapsulated in collagen type I inside microchannels of the microfluidic device. Then, they observed the effects of local heating induced by AuNPs on the developed endothelial model. The results showed that continuous exposure to heat, in fact, hindered the transport and it is associated with HSF1.

Concerning the use of nanoparticles, other improvements must be considered to overcome additional obstacles. Nanoparticles are subjected to different barriers once inside the human body. For example, the blood flow, the interactions with the endothelium and the interactions with other healthy cells, which usually are not consider. Moreover, the complex environment around the tumour, as the high interstitial fluid pressure and the dense extracellular matrix, has also hindered the transport, preventing the necessary amounts of nanoparticles to reach target places. One of the first barriers is endothelium. It was with this in mind that Chen et al. ${ }^{96}$ developed a model to test new drugs by using a microfluidic chip with the capacity to mimicry the endothelial wall and the tumour microenvironment. Within this setting, the authors observed that, although the drug delivery systems assessed, went through the endothelial wall of two different breast cancer types' scenarios, they showed different cancers' microenvironment penetration rates. Another barrier is the interaction with cells. For so, Tokárová et al. ${ }^{109}$ reported the use of a microfluidic device to study adhesion strength of nanoparticles to cells (Figure 7, B). Different approaches have been pursued to obtain an effective and strong adhesion to tumour cells, which ultimately, would improve the development of new chemotherapies. During this work, silica nanoparticles were modified with an antibody specific for the transmembrane protein, carbonic anhydrase IX $\left(\mathrm{SiO}_{2}-\mathrm{M} 75\right)$, which is express in tumour cells under hypoxic conditions. The results showed that the nanoparticles were small enough to pass through the large porous typical of new tumour vasculature, which is not observed in healthy tissue, and persisted adhered under flow rates similar to the ones observed in the tumour vasculature. Additionally, the results demonstrated that the strength of nanoparticles adhered to cancer cells was higher than non-specific modified nanoparticles. More recently, Jarvis et al. ${ }^{29}$ studied another barrier, the infiltration of nanoparticles used for drug delivery from the blood vessels until the tumour mass and throughout a tumour mass. In this interesting evaluation, they mimic blood vessels by culturing endothelial cells along an outer microchannel, and the tumour mass by culturing breast cancer cells within a Matrigel matrix inside an inner chamber. Then, this co-culture microfluidic device was perfused with camptothecin nanocrystals modified with folic acid, a target for breast cancer cells. The 
results indicated that despite the entire nanoparticles were only able to superficial penetrate the tumour mass, they dissolve, and this way, they can infiltrate further, inducing tumour cells' death along with the mass.

\section{Conclusions and future directions}

Traditional cancer diagnosis tools are still limited in their sensitivity and specificity. Therefore, new techniques have been pursued, such as the detection of CTCs and biomarkers.

On one hand, there is an incredible interest in the detection of CTCs due to their evident association with cancer progression. Several approaches concerning the use of EpCAM for CTCs detection were studied and even reach the clinic. But the addition of nanoparticles and microfluidic devices allowed to go further, enabling the capture and visualization of cells out of small amounts, and more efficiently than the commercially available. Even so, researchers have been showing that EpCAM expression may decrease during epithelial-mesenchymal transition or by mutation of the cells, which compromise the efficiency of those approaches. For so, new alternatives have been studied as the use of nucleic acid-based strategies to detect CTCs. These strategies showed to be more efficient and more sensitive than EpCAM based strategies. Furthermore, the use of nanoparticles and microfluidic devices showed to improve detection sensitivity as compared with assays performed in traditional microtubes.

On the other hand, the detection of biomarkers has sparkle cancer field due to its association with different cancer stages. The detection of single biomarkers within fluid samples, like EGFR, CEA, PSA, and K-Ras, or its simultaneous detection, have been studied to get a more accurate and reliable diagnostic tool. Even so, it is important to mention that higher sensitivity has been obtained for protein-based biomarkers detection as compared with nucleic acid-based biomarkers detection. Several approaches were tested to improve sensitivity and selectivity, as the use of signal amplification by using silver nanoparticles, gold nanoparticles, quantum dots, horseradish peroxidase or even a combination of them. The result of such approaches allowed the improvement of the limit of detection as compared with traditional methods. Additionally, it was also studied the presence of biomarkers directly from tissues from cancer patients since it can give important information for a more personalized therapy.

Despite the impressive progress made thus far that allowed to detect very small changes of biomarkers levels in a precise manner, the developed strategies have struggled to be approved by regulatory agencies (e.g. FDA) and to be used in the clinics. This can be justified by the lack of information regarding the safety of these strategies. Therefore, it is imperative to deepen the studies in a way they answer the main question raised by the FDA "is the product safe and effective?", to fasten new strategies translation. A different drawback is the cost associated with many strategies developed. Nowadays, the existing ones are expensive and the trend points to an increase in these prices. Furthermore, since the fabrication of microfluidic devices is mostly obtained by casting-based moulding approaches, it is difficult to fully automatize the entire process, resulting in an expensive and time-consuming process. Unfortunately, developing countries are the most affected. If the strategies developed to follow the same trend, they will not be accessible at all. For so, a new concern has arisen, i.e. the development of affordable point-of-care devices that ultimately would support clinical decisions are in great need. In this reasoning, new low-cost platforms have been developed. Most of them do not need any label to detect biomarkers, which minimizes the complexity and the cost associated with diagnostics. Additionally, these devices are easy to transport and store and enable fast and easy detection of specific biomarkers. Amongst the studied devices, paperbased devices have been showing to be a promising tool to achieve this goal. They do not need external devices to promote fluid transportation, are easily transportable and storable, and are easily disposable. Nevertheless, some drawbacks as the irregularity of paper and the uneven fibres still need to be surpassed. Additionally, a different strategy has been pursued, the use of 3D printing to develop cost-effective microfluidic devices. This approach allows obtaining complex structures with desired features within a small amount of time and with reduced cost. The designed microfluidic device can be obtained in a single step, layer-by-layer, from a computer-aided drawing file. Moreover, 3D printing techniques guarantee a more reproducible device as compared with traditional methods.

Although technology has developed towards new efficient and precise strategies, there are still many drawbacks to overcome, and finally, reach the clinic. Overall, the combination of nanoparticle and microfluidic research fields will enable us to engineer a new generation of point-of-care systems for early diagnosis that will certainly allow improving cancer treatment (personalized and cost-effective manner), in a near future.

\section{Acknowledgements}

F.R. Maia acknowledges Portuguese Foundation for Science and Technology (FCT) for her work contract under the Transitional Rule DL 57/2016 (CTTI-57/18-I3BS ${ }^{5}$ ). J. M. Oliveira thanks FCT for his distinction attributed under the FCT Investigator program (IF/01285/2015).

\section{References}

1. Stewart BW, Wild CP. World Cancer Report 2014: IARC.

2. Joyce JA, Pollard JW. Microenvironmental regulation of metastasis. Nat Rev Cancer 2009;9(4):239-52.

3. Ghazani AA, McDermott S, Pectasides M, Sebas M, Mino-Kenudson $\mathrm{M}$, Lee $\mathrm{H}$, et al. Comparison of select cancer biomarkers in human circulating and bulk tumor cells using magnetic nanoparticles and a miniaturized micro-NMR system. Nanomedicine 2013;9(7):1009-17.

4. Meric-Bernstam F, Mills GB. Overcoming implementation challenges of personalized cancer therapy. Nat Rev Clin Oncol 2012;9(9):542-8.

5. Krebs MG, Hou JM, Ward TH, Blackhall FH, Dive C. Circulating tumour cells: their utility in cancer management and predicting outcomes. Ther Adv Med Oncol 2010;2(6):351-65.

6. Miyamoto DT, Sequist LV, Lee RJ. Circulating tumour cellsmonitoring treatment response in prostate cancer. Nat Rev Clin Oncol 2014;11(7):401-12. 
7. Chakrabarty AM, Bernardes N, Fialho AM. Bacterial proteins and peptides in cancer therapy: today and tomorrow. Bioengineered 2014;5 (4):234-42.

8. Muller D. Antibody fusions with immunomodulatory proteins for cancer therapy. Pharmacol Ther 2015;154:57-66.

9. Zhu H, Li J, Zhang XB, Ye M, Tan W. Nucleic acid aptamer-mediated drug delivery for targeted cancer therapy. ChemMedChem 2015;10 (1):39-45.

10. Patel PL, Rana NK. Patel MR. Sabatino D. Nucleic Acid Bioconjugates in Cancer Detection and Therapy. ChemMedChem: Kozuch SD; 2015.

11. Xu X, Farach-Carson MC, Jia X. Three-dimensional in vitro tumor models for cancer research and drug evaluation. Biotechnology advances 2014;32(7):1256-68.

12. Carvalho MR, Lima D, Reis RL, Correlo VM, Oliveira JM. Evaluating Biomaterial- and Microfluidic-Based 3D Tumor Models. Trends in biotechnology 2015;33(11):667-78.

13. Virupakshappa B. Applications of nanomedicine in oral cancer. Oral Health Dent Manag 2012;11(2):62-8.

14. Boulaiz H, Alvarez PJ, Ramirez A, Marchal JA, Prados J, RodriguezSerrano F, et al. Nanomedicine: application areas and development prospects. Int J Mol Sci 2011;12(5):3303-21.

15. Jain A, Cheng K. The principles and applications of avidin-based nanoparticles in drug delivery and diagnosis. Journal of Controlled Release 2017;245:27-40.

16. Zhang X, Zhang H, Yin L, Hu R, Qiu T, Yin Y, et al. A pH-sensitive nanosystem based on carboxymethyl chitosan for tumor-targeted delivery of daunorubicin. Journal of biomedical nanotechnology 2016;12(8):1688-98.

17. Wei X, Liao J, Davoudi Z, Zheng H, Chen J, Li D, et al. Folate receptortargeted and GSH-responsive carboxymethyl chitosan nanoparticles containing covalently entrapped 6-mercaptopurine for enhanced intracellular drug delivery in leukemia. Mar Drugs 2018;16(11):439.

18. Nakamura Y, Mochida A, Choyke PL, Kobayashi H. Nanodrug delivery: is the enhanced permeability and retention effect sufficient for curing cancer? Bioconjugate Chemistry 2016;27(10):2225-38.

19. Peng H, Liu X, Wang G, Li M, Bratlie KM, Cochran E, et al. Polymeric multifunctional nanomaterials for theranostics. Journal of Materials Chemistry B 2015;3(34):6856-70

20. Wang Q, Cheng H, Peng H, Zhou H, Li PY, Langer R. Non-genetic engineering of cells for drug delivery and cell-based therapy. Advanced Drug Delivery Reviews 2015;91:125-40.

21. Brigger I, Dubernet C, Couvreur P. Nanoparticles in cancer therapy and diagnosis. Advanced Drug Delivery Reviews 2012;64:24-36.

22. Valencia PM, Farokhzad OC, Karnik R, Langer R. Microfluidic technologies for accelerating the clinical translation of nanoparticles. Nature Nanotechnology 2012;7:623.

23. Muluneh M, Issadore D. Microchip-based detection of magnetically labeled cancer biomarkers. Adv Drug Deliv Rev 2014;66:101-9.

24. Bellan LM, Wu D, Langer RS. Current trends in nanobiosensor technology. Wiley interdisciplinary reviews Nanomedicine and nanobiotechnology 2011;3(3):229-46.

25. Yun H, Kim K, Lee WG. Cell manipulation in microfluidics. Biofabrication 2013;5(2)022001

26. Rusling JF, Bishop GW, Doan N, Papadimitrakopoulos F. Nanomaterials and biomaterials in electrochemical arrays for protein detection. $\mathrm{J}$ Mater Chem B Mater Biol Med. 2014;2(1).

27. Devi RV, Doble M, Verma RS. Nanomaterials for early detection of cancer biomarker with special emphasis on gold nanoparticles in immunoassays/sensors. Biosensors \& bioelectronics 2015;68:688-98.

28. Kwak B, Ozcelikkale A, Shin CS, Park K, Han B. Simulation of complex transport of nanoparticles around a tumor using tumormicroenvironment-on-chip. J Control Release 2014;194:157-67.

29. Jarvis M, Arnold M, Ott J, Pant K, Prabhakarpandian B, Mitragotri S. Microfluidic co-culture devices to assess penetration of nanoparticles into cancer cell mass. Bioengineering \& translational medicine 2017;2 (3):268-77.
30. Pohlmann ES, Patel K, Guo S, Dukes MJ, Sheng Z, Kelly DF. Realtime visualization of nanoparticles interacting with glioblastoma stem cells. Nano letters 2015;15(4):2329-35.

31. Zhai Z, Nie M, Guan Y, Zhang F, Chen L. Muhammad, et al. A microfluidic surface-enhanced Raman spectroscopy approach for assessing the particle number effect of AgNPs on cytotoxicity Ecotoxicology and Environmental Safety 2018;162:529-35.

32. Carvalho MR, Maia FR, Silva-Correia J, Costa BM, Reis RL, Oliveira JM. A semiautomated microfluidic platform for real-time investigation of nanoparticles' cellular uptake and cancer cells' tracking. Nanomedicine 2017;12(6):581-96.

33. Hui YY, Su LJ, Chen OY, Chen YT, Liu TM, Chang HC. Wide-field imaging and flow cytometric analysis of cancer cells in blood by fluorescent nanodiamond labeling and time gating. Scientific reports 2014; $4: 5574$

34. He R, Zhao L, Liu Y, Zhang N, Cheng B, He Z, et al. Biocompatible $\mathrm{TiO} 2$ nanoparticle-based cell immunoassay for circulating tumor cells capture and identification from cancer patients. Biomedical microdevices 2013;15(4):617-26.

35. Zhang H, Fu X, Hu J, Zhu Z. Microfluidic bead-based multienzymenanoparticle amplification for detection of circulating tumor cells in the blood using quantum dots labels. Analytica chimica acta 2013;779:64-71.

36. Varillas JI, Zhang J, Chen K, Barnes II, Liu C, George TJ, et al. Microfluidic Isolation of Circulating Tumor Cells and Cancer StemLike Cells from Patients with Pancreatic Ductal Adenocarcinoma. Theranostics 2019;9(5):1417-25.

37. Burinaru TA, Avram M, Avram A, Mărculescu C, Ţîncu B, Ţucureanu $\mathrm{V}$, et al. Detection of circulating tumor cells using microfluidics. ACS Combinatorial Science 2018;20(3):107-26.

38. Wang S, Liu K, Liu J, Yu ZTF, Xu X, Zhao L, et al. Highly efficient capture of circulating tumor cells using nanostructured silicon substrates with integrated chaotic micromixers. Angewandte Chemie (International ed in English) 2011;50(13):3084-8.

39. Pantel K, Riethdorf S. Pathology: Are circulating tumor cells predictive of overall survival? Nat Rev Clin Oncol 2009;6(4):190-1.

40. Zhang L, Ridgway LD, Wetzel MD, Ngo J, Yin W, Kumar D, et al. The Identification and Characterization of Breast Cancer CTCs Competent for Brain Metastasis. Science Translational Medicine. 2013;5 (180):180ra48-ra48.

41. Xiao Y, Zhou H, Xuan N, Cheng M, Rao Y, Luo Y, et al. Effective and selective cell retention and recovery from whole blood by electroactive thin films. ACS Appl Mater Interfaces 2014;6(23):20804-11.

42. Earhart CM, Hughes CE, Gaster RS, Ooi CC, Wilson RJ, Zhou LY, et al. Isolation and mutational analysis of circulating tumor cells from lung cancer patients with magnetic sifters and biochips. Lab on a chip 2014;14(1):78-88.

43. Wang C, Ye M, Cheng L, Li R, Zhu W, Shi Z, et al. Simultaneous isolation and detection of circulating tumor cells with a microfluidic silicon-nanowire-array integrated with magnetic upconversion nanoprobes. Biomaterials 2015;54:55-62.

44. Mohamadi RM, Besant JD, Mepham A, Green B, Mahmoudian L, Gibbs T, et al. Nanoparticle-mediated binning and profiling of heterogeneous circulating tumor cell subpopulations. Angew Chem Int Ed Engl 2015;54(1):139-43.

45. Green BJ, Kermanshah L, Labib M, Ahmed SU, Silva PN, Mahmoudian L, et al. Isolation of phenotypically distinct cancer cells using nanoparticle-mediated sorting. ACS applied materials \& interfaces 2017;9(24):20435-43.

46. Green BJ, Nguyen V, Atenafu E, Weeber P, Duong BTV, Thiagalingam $\mathrm{P}$, et al. Phenotypic profiling of circulating tumor cells in metastatic prostate cancer patients using nanoparticle-mediated ranking. Analytical chemistry 2019;91(15):9348-55.

47. Huang YY, Chen P, Wu CH, Hoshino K, Sokolov K, Lane N, et al. Screening and molecular analysis of single circulating tumor cells using micromagnet array. Scientific reports 2015;5:16047. 
48. Sheng W, Chen T, Tan W, Fan ZH. Multivalent DNA nanospheres for enhanced capture of cancer cells in microfluidic devices. ACS Nano 2013;7(8):7067-76.

49. Song Y, Shi Y, Huang M, Wang W, Wang Y, Cheng J, et al. Bioinspired engineering of a multivalent aptamer-functionalized nanointerface to enhance the capture and release of circulating tumor cells. Angewandte Chemie International Edition 2019;58(8):2236-40.

50. Kotagiri N, Li Z, Xu X, Mondal S, Nehorai A, Achilefu S. Antibody quantum dot conjugates developed via copper-free click chemistry for rapid analysis of biological samples using a microfluidic microsphere array system. Bioconjug Chem 2014;25(7):1272-81.

51. Hu M, He Y, Song S, Yan J, Lu HT, Weng LX, et al. DNA-bridged bioconjugation of fluorescent quantum dots for highly sensitive microfluidic protein chips. Chem Commun (Camb) 2010;46 (33):6126-8

52. Yan J, Pan D, Zhu C, Wang L, Song S, Fan C. A gold nanoparticlebased microfluidic protein chip for tumor markers. J Nanosci Nanotechnol 2009;9(2):1194-7.

53. Giuffrida MC, Cigliana G, Spoto G. Ultrasensitive detection of lysozyme in droplet-based microfluidic devices. Biosensors and Bioelectronics 2018;104:8-14.

54. Ortega FG, Fernández-Baldo MA, Serrano MJ, Messina GA, Lorente JA, Raba J. Epithelial cancer biomarker EpCAM determination in peripheral blood samples using a microfluidic immunosensor based in silver nanoparticles as platform. Sensors and Actuators B: Chemical 2015;221:248-56.

55. Bravo K, Ortega FG, Messina GA, Sanz MI, Fernandez-Baldo MA, Raba J. Integrated bio-affinity nano-platform into a microfluidic immunosensor based on monoclonal bispecific trifunctional antibodies for the electrochemical determination of epithelial cancer biomarker. Clinica chimica acta; international journal of clinical chemistry. 2017;464:64-71.

56. Seenivasan R, Singh CK, Warrick JW, Ahmad N, Gunasekaran S. Microfluidic-integrated patterned ITO immunosensor for rapid detection of prostate-specific membrane antigen biomarker in prostate cancer. Biosensors \& bioelectronics 2017;95:160-7.

57. Li S, Wan Y, Su Y, Fan C, Bhethanabotla VR. Gold nanoparticle-based low limit of detection love wave biosensor for carcinoembryonic antigens. Biosensors \& bioelectronics 2017;95:48-54.

58. Yu X, Xia HS, Sun ZD, Lin Y, Wang K, Yu J, et al. On-chip dual detection of cancer biomarkers directly in serum based on selfassembled magnetic bead patterns and quantum dots. Biosensors \& bioelectronics 2013;41:129-36.

59. Zhang H, Liu L, Fu X, Zhu Z. Microfluidic beads-based immunosensor for sensitive detection of cancer biomarker proteins using multienzymenanoparticle amplification and quantum dots labels. Biosensors \& bioelectronics 2013;42:23-30.

60. Hu M, Yan J, He Y, Lu H, Weng L, Song S, et al. Ultrasensitive, multiplexed detection of cancer biomarkers directly in serum by using a quantum dot-based microfluidic protein chip. ACS Nano 2010;4(1):488-94.

61. Ko YJ, Maeng JH, Ahn Y, Hwang SY, Cho NG, Lee SH. Microchipbased multiplex electro-immunosensing system for the detection of cancer biomarkers. Electrophoresis 2008;29(16):3466-76.

62. Jokerst JV, Raamanathan A, Christodoulides N, Floriano PN, Pollard AA, Simmons GW, et al. Nano-bio-chips for high performance multiplexed protein detection: determinations of cancer biomarkers in serum and saliva using quantum dot bioconjugate labels. Biosensors \& bioelectronics 2009;24(12):3622-9.

63. Noh HN, Kim JS. Detection of K-Ras oncogene using magnetic beadsquantum dots in microfluidic chip. J Nanosci Nanotechnol 2013;13 (8):5240-4.

64. Ankireddy SR, Kim J. A microfluidic microbeads fluorescence assay with quantum dots-bead-DNA probe. Journal of nanoscience and nanotechnology 2016;16(3):2897-9.

65. Roy S, Soh JH, Gao Z. A microfluidic-assisted microarray for ultrasensitive detection of miRNA under an optical microscope. $L a b$ on a chip 2011;11(11):1886-94.
66. Pawar RS, Upadhaya PG, Patravale VB. Chapter 34 - Quantum Dots: Novel Realm in Biomedical and Pharmaceutical Industry. In: Mustansar Hussain C, editor. Handbook of Nanomaterials for Industrial Applications: Elsevier; 2018. p. 621-37.

67. Chandran PR, Thomas RT. Chapter 14 - Gold Nanoparticles in Cancer Drug Delivery. In: Thomas S, Grohens Y, Ninan N, editors. Nanotechnology Applications for Tissue Engineering. Oxford: William Andrew Publishing; 2015. p. 221-37.

68. Zhang X-F, Liu Z-G, Shen W, Gurunathan S. Silver nanoparticles: synthesis, characterization, properties, applications, and therapeutic approaches. Int J Mol Sci 2016;17(9):1534.

69. Leon SA, Shapiro B, Sklaroff DM, Yaros MJ. Free DNA in the serum of cancer patients and the effect of therapy. Cancer research 1977;37 (3):646-50.

70. Stroun M, Anker P, Maurice P, Lyautey J, Lederrey C, Beljanski M. Neoplastic characteristics of the DNA found in the plasma of cancer patients. Oncology 1989;46(5):318-22.

71. Sorenson GD, Pribish DM, Valone FH, Memoli VA, Bzik DJ, Yao SL. Soluble normal and mutated DNA sequences from single-copy genes in human blood. Cancer epidemiology, biomarkers \& prevention : a publication of the American Association for Cancer Research, cosponsored by the American Society of Preventive Oncology 1994;3 (1):67-71.

72. Kwon S, Kim MS, Lee ES, Sohn JS, Park JK. A quantum dot-based microfluidic multi-window platform for quantifying the biomarkers of breast cancer cells. Integr Biol (Camb) 2014;6(4):430-7.

73. Kwon S, Cho CH, Lee ES, Park JK. Automated measurement of multiple cancer biomarkers using quantum-dot-based microfluidic immunohistochemistry. Analytical chemistry 2015;87(8):4177-83.

74. Wei B, Mao K, Liu N, Zhang M, Yang Z. Graphene nanocomposites modified electrochemical aptamer sensor for rapid and highly sensitive detection of prostate specific antigen. Biosensors \& bioelectronics 2018;121:41-6.

75. Wang Y, Luo J, Liu J, Sun S, Xiong Y, Ma Y, et al. Label-free microfluidic paper-based electrochemical aptasensor for ultrasensitive and simultaneous multiplexed detection of cancer biomarkers. Biosensors and Bioelectronics 2019;136:84-90.

76. Wang Y, Ge L, Wang P, Yan M, Yu J, Ge S. A three-dimensional origami-based immuno-biofuel cell for self-powered, low-cost, and sensitive point-of-care testing. Chem Commun (Camb) 2014;50 (16):1947-9.

77. Bahavarnia F, Saadati A, Hassanpour S, Hasanzadeh M, Shadjou N, Hassanzadeh A. Paper based immunosensing of ovarian cancer tumor protein CA 125 using novel nano-ink: A new platform for efficient diagnosis of cancer and biomedical analysis using microfluidic paperbased analytical devices ( $\mu \mathrm{PAD})$. International Journal of Biological Macromolecules 2019;138:744-54.

78. Wu Y, Xue P, Kang Y, Hui KM. Paper-based microfluidic electrochemical immunodevice integrated with nanobioprobes onto graphene film for ultrasensitive multiplexed detection of cancer biomarkers. Analytical chemistry 2013;85(18):8661-8.

79. Fan Y, Liu J, Wang Y, Luo J, Xu H, Xu S, et al. A wireless point-ofcare testing system for the detection of neuron-specific enolase with microfluidic paper-based analytical devices. Biosensors \& bioelectronics 2017;95:60-6.

80. Hu SW, Xu BY, Ye WK, Xia XH, Chen HY, Xu JJ. Versatile microfluidic droplets array for bioanalysis. ACS Appl Mater Interfaces 2015;7(1):935-40.

81. Wu MS, Liu Z, Shi HW, Chen HY, Xu JJ. Visual electrochemiluminescence detection of cancer biomarkers on a closed bipolar electrode array chip. Analytical chemistry 2015;87(1):530-7.

82. Kadimisetty K, Malla S, Sardesai NP, Joshi AA, Faria RC, Lee NH, et al. Automated multiplexed ECL Immunoarrays for cancer biomarker proteins. Analytical chemistry 2015;87(8):4472-8.

83. Liu W, Zhang Y, Ge S, Song X, Huang J, Yan M, et al. Core-shell Fe3O4-Au magnetic nanoparticles based nonenzymatic ultrasensitive 
electrochemiluminescence immunosensor using quantum dots functionalized graphene sheet as labels. Analytica chimica acta 2013;770:132-9.

84. Li W, Ge S, Wang S, Yan M, Ge L, Yu J. Highly sensitive chemiluminescence immunoassay on chitosan membrane modified paper platform using $\mathrm{TiO} 2$ nanoparticles/multiwalled carbon nanotubes as label. Luminescence 2013;28(4):496-502.

85. Chen Y, Guo X, Liu W, Zhang L. Paper-based fluorometric immunodevice with quantum-dot labeled antibodies for simultaneous detection of carcinoembryonic antigen and prostate specific antigen. Mikrochimica acta 2019;186(2):112.

86. Gao B, Liu H, Gu Z. Patterned photonic nitrocellulose for pseudo-paper microfluidics. Analytical chemistry 2016;88(10):5424-9.

87. Kadimisetty K, Mosa IM, Malla S, Satterwhite-Warden JE, Kuhns TM, Faria RC, et al. 3D-printed supercapacitor-powered electrochemiluminescent protein immunoarray. Biosensors \& bioelectronics 2016;77:188-93.

88. Kadimisetty K, Malla S, Bhalerao KS, Mosa IM, Bhakta S, Lee NH, et al. Automated 3D-Printed Microfluidic Array for Rapid NanomaterialEnhanced Detection of Multiple Proteins. 2018;90(12):7569-77.

89. Barbosa AI, Wichers JH, van Amerongen A, Reis NM. Towards onestep quantitation of prostate-specific antigen (PSA) in microfluidic devices: feasibility of optical detection with nanoparticle labels. BioNanoScience 2017;7(4):718-26.

90. . Available from: https://www.fda.gov/drugs/resources-informationapproved-drugs/hematologyoncology-cancer-approvals-safetynotifications.

91. Zhao L, Caot JT, Wu ZQ, Li JX, Zhu JJ. Lab-on-a-chip for anticancer drug screening using quantum dots probe based apoptosis assay. Journal of biomedical nanotechnology 2013;9(3):348-56.

92. Carvalho MR, Maia FR, Vieira S, Reis RL, Oliveira JM. Tuning enzymatically crosslinked silk fibroin hydrogel properties for the development of a colorectal cancer extravasation 3D model on a chip. Global Challenges 2018;2(5-6):1700100.

93. Yang Y, Yang X, Zou J, Jia C, Hu Y, Du H, et al. Evaluation of photodynamic therapy efficiency using an in vitro three-dimensional microfluidic breast cancer tissue model. Lab on a chip 2015;15 (3):735-44.

94. Kalinowska D, Grabowska-Jadach I, Liwinska M, Drozd M, Pietrzak M, Dybko A, et al. Studies on effectiveness of PTT on 3D tumor model under microfluidic conditions using aptamer-modified nanoshells. Biosensors and Bioelectronics 2019;126:214-21.

95. DeWitt MR, Rylander MN. Tunable Collagen Microfluidic Platform to Study Nanoparticle Transport in the Tumor Microenvironment. In: Sirianni RW, Behkam B, editors. Targeted Drug Delivery: Methods and Protocols. New York, NY: Springer US; 2018. p. 159-78.
96. Chen Y, Gao D, Wang Y, Lin S, Jiang Y. A novel 3D breast-cancer-onchip platform for therapeutic evaluation of drug delivery systems. Analytica chimica acta 2018;1036:97-106.

97. Krause CE, Otieno BA, Bishop GW, Phadke G, Choquette L, Lalla RV, et al. Ultrasensitive microfluidic array for serum pro-inflammatory cytokines and C-reactive protein to assess oral mucositis risk in cancer patients. Anal Bioanal Chem 2015;407(23):7239-43.

98. Sarfati G, Dvir T, Elkabets M, Apte RN, Cohen S. Targeting of polymeric nanoparticles to lung metastases by surface-attachment of YIGSR peptide from laminin. Biomaterials 2011;32(1):152-61.

99. Terranova VP, Liotta LA, Russo RG, Martin GR. Role of laminin in the attachment and metastasis of murine tumor cells. Cancer Res 1982;42 (6):2265-9.

100. Liotta LA. Tumor invasion and metastases: role of the basement membrane. Warner-Lambert Parke-Davis Award lecture. The American Journal of Pathology 1984;117(3):339-48.

101. Kolhar P, Anselmo AC, Gupta V, Pant K, Prabhakarpandian B, Ruoslahti E, et al. Using shape effects to target antibody-coated nanoparticles to lung and brain endothelium. Proceedings of the National Academy of Sciences of the United States of America 2013;110(26):10753-8.

102. Di D, Chen L, Wang L, Sun P, Liu Y, Xu Z, et al. Downregulation of human intercellular adhesion molecule-1 attenuates the metastatic ability in human breast cancer cell lines. Oncol Rep 2016;35(3):1541-8.

103. Usami Y, Ishida K, Sato S, Kishino M, Kiryu M, Ogawa Y, et al. Intercellular adhesion molecule-1 (ICAM-1) expression correlates with oral cancer progression and induces macrophage/cancer cell adhesion. International journal of cancer 2013;133(3):568-78.

104. Kilinc D, Lesniak A, Rashdan SA, Gandhi D, Blasiak A, Fannin PC, et al. Mechanochemical stimulation of MCF7 cells with rod-shaped FeAu Janus particles induces cell death through paradoxical hyperactivation of ERK. Advanced healthcare materials 2015;4(3):395-404.

105. Roskoski Jr R. The ErbB/HER family of protein-tyrosine kinases and cancer. Pharmacological Research 2014;79:34-74.

106 Akerfelt M, Morimoto RI, Sistonen L. Heat shock factors: integrators of cell stress, development and lifespan. Nat Rev Mol Cell Biol 2010;11 (8):545-55

107. Mendillo ML, Santagata S, Koeva M, Bell GW, Hu R, Tamimi RM, et al. HSF1 drives a transcriptional program distinct from heat shock to support highly malignant human cancers. Cell 2012;150(3):549-62.

108. Bagley AF, Scherz-Shouval R, Galie PA, Zhang AQ, Wyckoff J, Whitesell L, et al. Endothelial thermotolerance impairs nanoparticle transport in tumors. Cancer Res 2015;75(16):3255-67.

109. Tokarova V, Pittermannova A, Kral V, Rezacova P, Stepanek F. Feasibility and constraints of particle targeting using the antigenantibody interaction. Nanoscale 2013;5(23):11490-8. 